\title{
Characteristics of geomagnetic sudden commencement observed in middle and low latitudes
}

\author{
Satoru Tsunomura \\ Kakioka Magnetic Observatory, Kakioka 595, Yasato, Niihari, Ibaraki 315-0116, Japan
}

(Received February 12, 1998; Revised May 25, 1998; Accepted June 8, 1998)

\begin{abstract}
Characteristics of geomagnetic sudden commencement (SC) observed in middle and low latitudes are discussed on the basis of data analyses of magnetic variations and a numerical calculation. From the data analyses, it is found that a negative impulse is usually superposed on the main impulse of SC in $H$ component just after its onset, at the stations in middle to high latitudes in the local time range from the morning to the early afternoon. The superposition of the negative impulse causes the decrease of SC amplitude in $H$ component with increasing latitude in this area. The occurrence of the negative impulse does not seem to be dependent on geomagnetic activity. Examining a case study and a numerical analysis, it is suggested that this negative impulse is a signature of the magnetic variation due to the polar-originated ionospheric current system responsible for the main impulse of SC $\left(\mathrm{DP}_{\mathrm{MI}}\right)$. The discussion includes the possible interpretation of PPI introduced by Kikuchi and Araki (1985) and the availability of $D$ component magnetic data in middle latitude for a rough estimation of the magnetosphere-ionosphere coupling process.
\end{abstract}

\section{Introduction}

Geomagnetic disturbances observed in middle and low latitudes show less spatial irregularities than those in high latitudes because these regions are distant from the origins of disturbance. As used to derive $D s t$ index, the magnetic variations in low latitudes are usually regarded as representing the whole magnetospheric process without severe locality. However, the magnetic disturbances in middle and low latitudes have rather complicated time change and/or spatial variation although the variation forms look simple. There might be a possibility that some geomagnetic phenomena are not recognized because of the masking by the established "usual" variations.

Meanwhile, on the basis of extensive magnetic observations in middle and low latitudes, new findings of geomagnetic phenomena and/or confirmations for the existing models and theories have been obtained recently (e.g. Yumoto et al., 1992, 1996; Itonaga et al., 1995). Quantitative analysis on the basis of data analysis along with the computer simulation is now and will be further developed in the SRAMP period to clarify more precisely the processes in the magnetosphere and the ionosphere. Before developing the quantitative analysis of a geomagnetic disturbance, however, it is useful to reevaluate whether the spatial distribution or time change of the disturbance field can be explained on the basis of the existing model consistently; it is desirable that the explanation is on the quantitative basis. As a common feature in the actual applying of the existing models to the observed phenomena, the degree of relative contribution of the ionospheric current system against the magnetospheric pro-

Copy right (C) The Society of Geomagnetism and Earth, Planetary and Space Sciences (SGEPSS); The Seismological Society of Japan; The Volcanological Society of Japan; The Geodetic Society of Japan; The Japanese Society for Planetary Sciences. cess in the ground magnetic observation may become one of the important matters.

The characteristics of storm sudden commencement (SSC) and/or sudden impulse (SI) are a good subject to examine in these senses. As a method to examine the earth's magnetic response to a sudden increase of the solar wind dynamic pressure, many authors investigated the characteristics of SSC and SI (Araki, 1994 and references therein). Since the physical process of the onset is basically the same for SSC and SI, some authors call them "SC (sudden commencement)" without distinction. In this paper I will use this terminology.

For explaining the global distribution of magnetic variations of SC, Araki (1977) introduced the ionospheric current system model of polar origin $\left(\mathrm{DP}_{\mathrm{PRI}}\right.$ and $\mathrm{DP}_{\mathrm{MI}}$ in his model) as a superposing effect on the magnetospheric com-

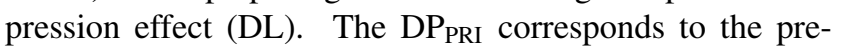
liminary reverse impulse (PRI) and $\mathrm{DP}_{\mathrm{MI}}$ the main impulse (MI) of SC. Kikuchi and Araki (1979) proved that the polar electric field associated with an SC is instantaneously transmitted to the equator with the speed of light by the zerothorder TM mode of electromagnetic wave propagating in the earth-ionosphere wave-guide. Tsunomura and Araki (1984) showed that the polar-originated ionospheric current system extending to the dayside equator makes observable magnetic variations in the dayside middle latitudes. The appearance of the polar-originated electric field associated with SC in low latitudes and/or the equator is evidenced by various observational results (Kikuchi et al., 1985; Kikuchi, 1986; Sastri et al., 1993). Araki (1994) presented a synthesized morphological interpretation for SC.

However, there remain some unsolved features of SC in middle and low latitudes. Tsunomura (1995) mentioned that the conversion of magnetic data to the geomagnetic dipole coordinate system is important to investigate the observed 


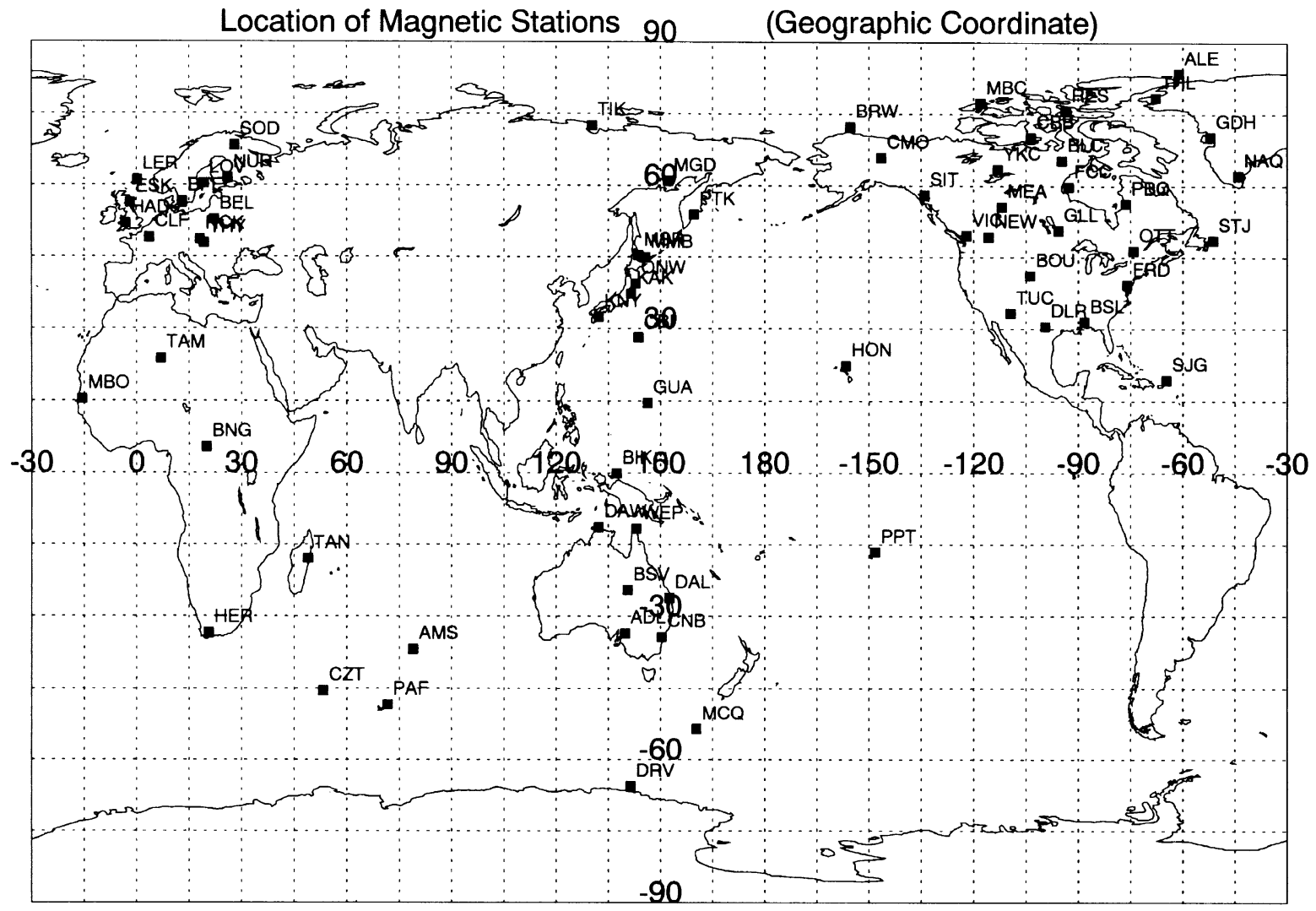

Fig. 1. Locations of the magnetic stations used in this study.

SSC, SIt- (Dipole frame) for $>5 n T(1985-92):$ Int. $=10$ min.
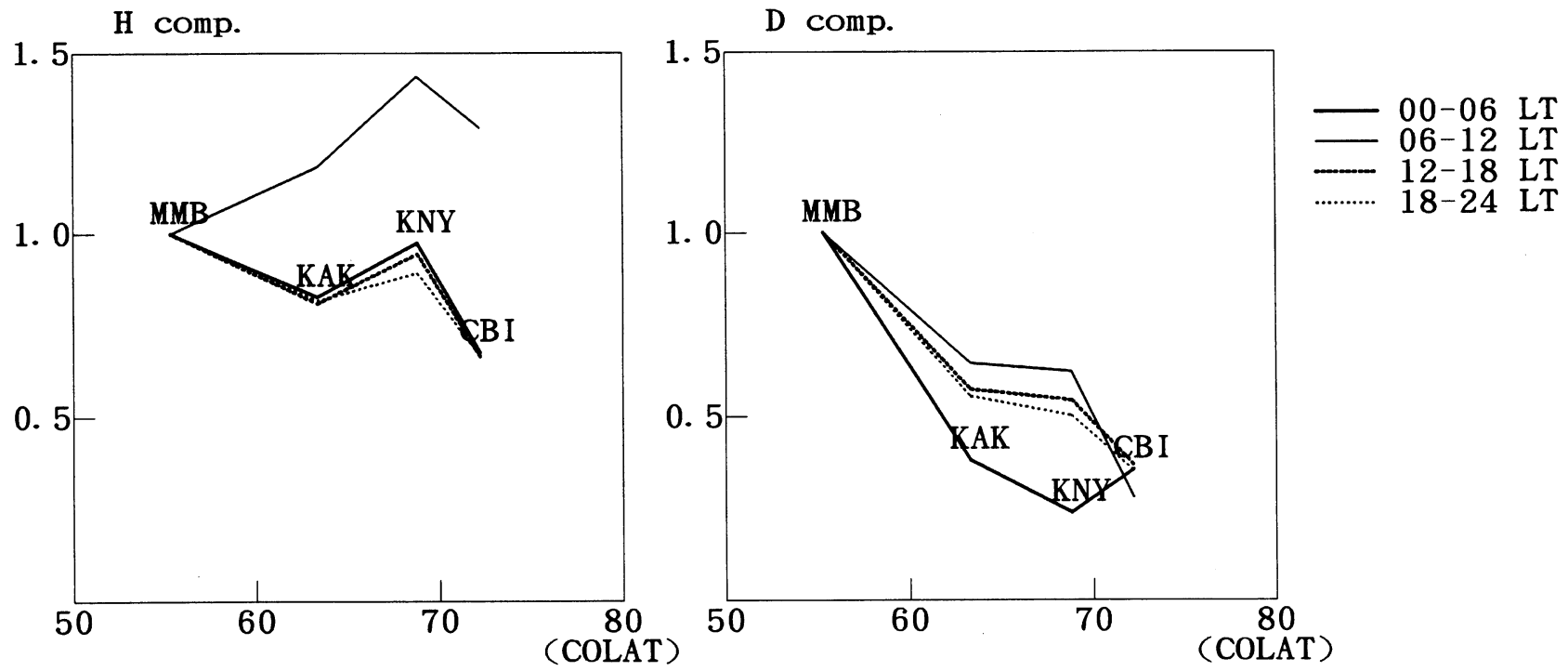

Fig. 2. Latitudinal variations in the average ratios of MI amplitude at KAK, KNY and CBI to that at MMB for SC's with the amplitude larger than 5 nT at KAK from 1985 to 1992 . The graphs are divided for four local time ranges of local time based on JST. 


\section{Ratio of $\mathrm{H}$ component}

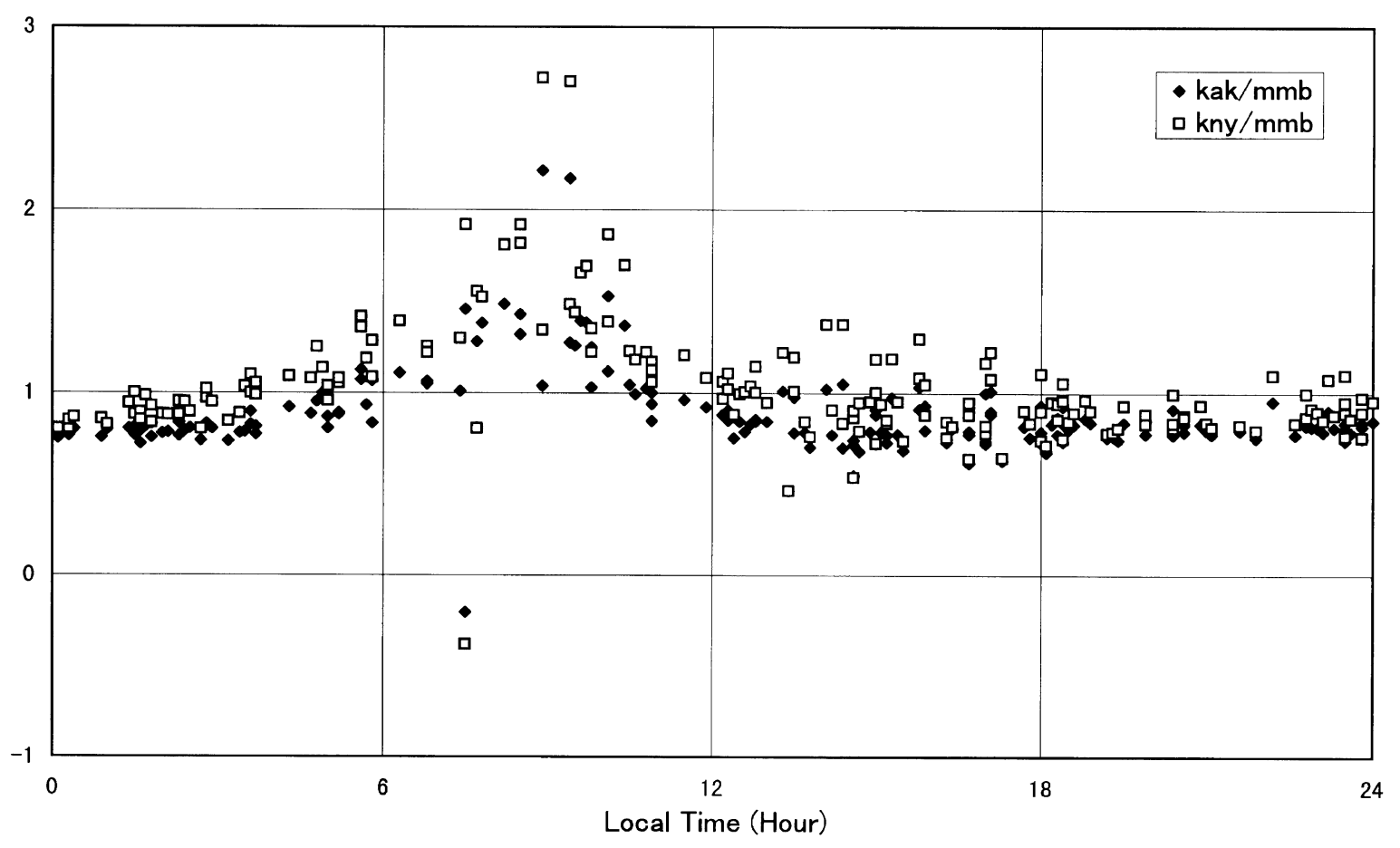

Fig. 3(a). Local time variation in the ratio of MI amplitude of $H$ component at KAK and KNY to that at MMB for SC's same as for Fig. 2.

Ratio of D component

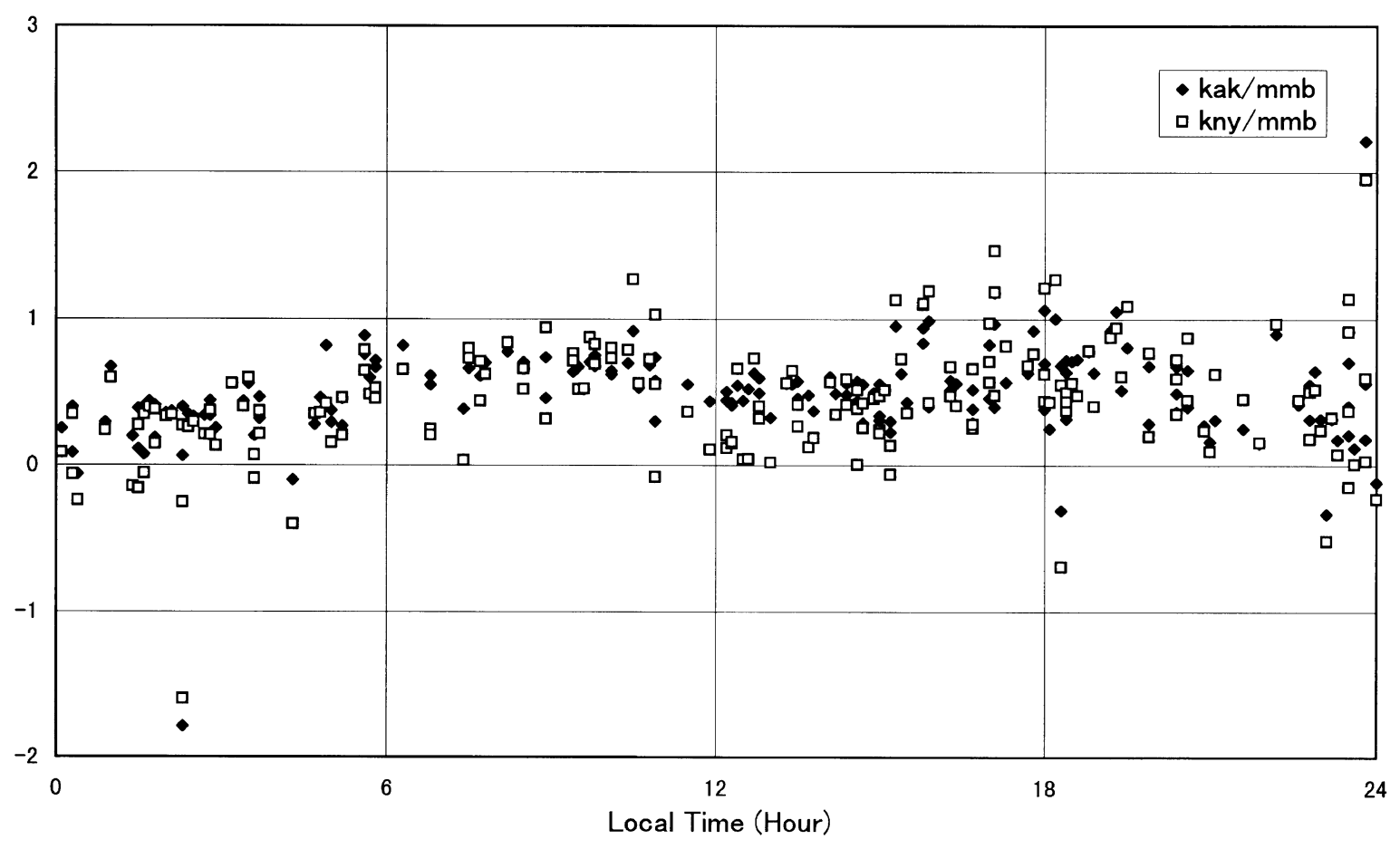

Fig. 3(b). Same as Fig. 3(a) for $D$ component. 


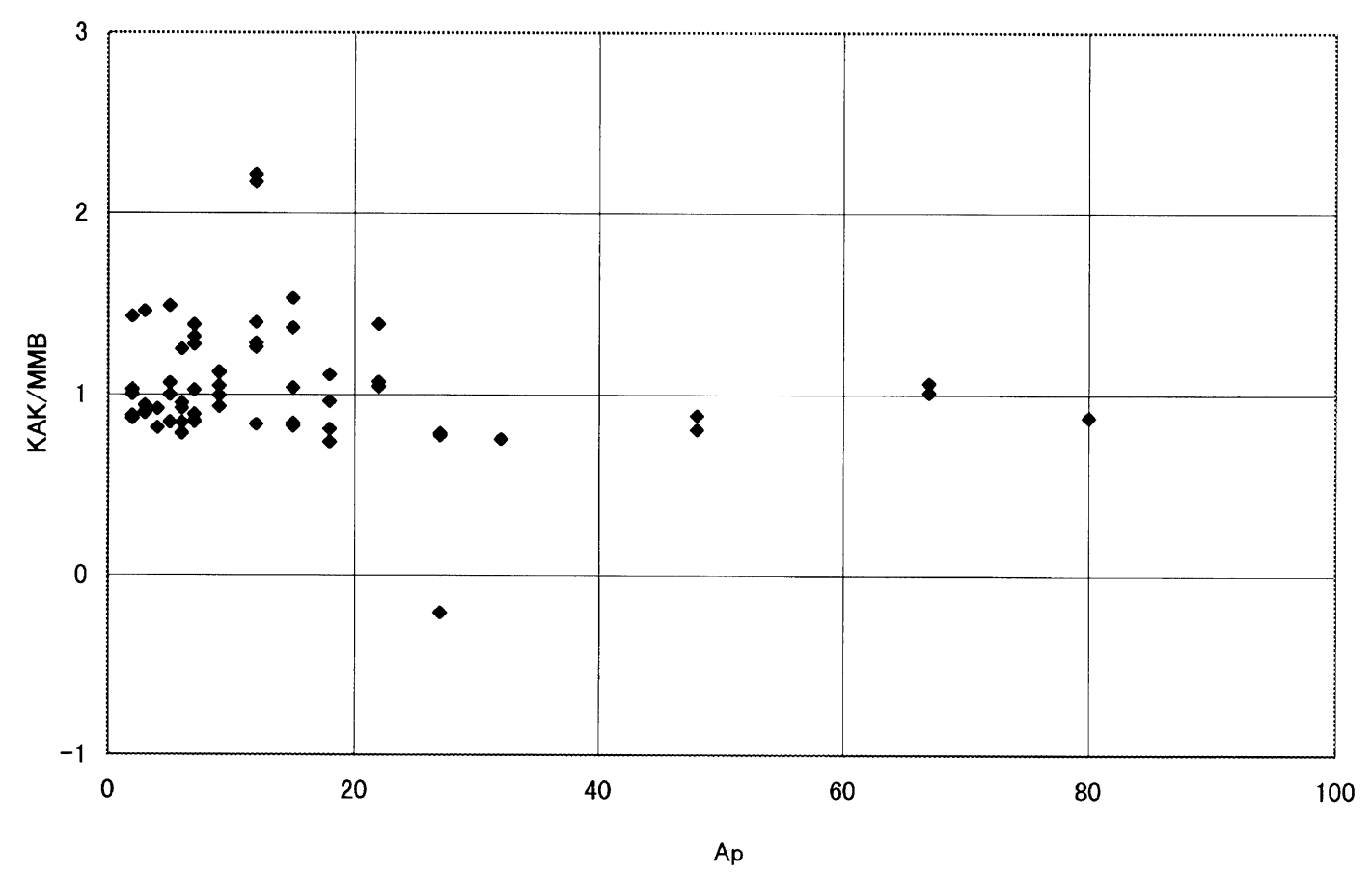

Fig. 4. Ap dependence of the ratio of MI amplitude in $H$ component at KAK to that at MMB for SC's picked up for the local time interval from 03 LT to 13 LT in JST.

characteristics in $D$ component of SC. In the course of his discussion, he showed that the latitudinal variation form of the amplitude of SC in $H$ component in the local time range from 06 to 12 LT is different from those in other local time ranges. He also showed that the variation form consists of pulse-like structures at the stations in middle latitude in that local time range. This fact cannot be explained straightforward by the Araki (1977)'s model and is interesting in relation with PPI (Preliminary Positive Impulse) of SC, often observed in the local time range from the morning to the afternoon (Kikuchi and Araki, 1985). The PPI is also one of the unsolved features associated with SC. Tsunomura (1995) tried to explain the observed features using a result of a numerical calculation of the ionospheric current system and partly succeeded. However, the equivalent currents should be derived in comparing with observations to clarify the relative contributions of $\mathrm{DL}$ and $\mathrm{DP}_{\mathrm{MI}}$ to the ground observations.

For the quantitative analysis of the DL field, the analytical model of the magnetosphere is successfully used for the estimation of the fields (Russell et al., 1994a, b). On the other hand, those for $\mathrm{DP}_{\mathrm{PRI}}$ and $\mathrm{DP}_{\mathrm{MI}}$ fields are not in the stage to predict the magnetic effects from the solar wind parameters. The investigation of the property of these fields is useful for the development of the quantitative understanding of the SC.

In this paper, I will develop similar analyses as Tsunomura (1995), extending the area of the magnetic observation and on the basis of the simulation result of the equivalent current system. And then discussions on the above matters and a possible interpretation of PPI will be given.

\section{Characteristics of SC in Middle and Low Lati- tudes}

Locations of the magnetic stations used in this study are shown in Fig. 1. Here the stations of the $210^{\circ}$ magnetic meridian observatory network (Yumoto et al., 1992, 1996) are included along with the routine observatories. At some of the routine observatories, one-minute values of three components of magnetic field vector are reported in the form of horizontal component, declination and vertical component. The second item is an angle while the others are magnetic flux density. To discuss geomagnetic phenomena physically, the former two are usually converted to the geomagnetically northward $(H)$ and eastward $(D)$ components of magnetic flux density. At the stations operated under a special scientific project such as the $210^{\circ}$ magnetic meridian observatory network, the data are reported as $H$ and $D$ components automatically. There are others types of the routine magnetic observatories from which the data are reported in the form of the geographically northward $(X)$, eastward $(Y)$ and vertical $(Z)$ components of the magnetic flux density.

Tsunomura (1995) mentioned that conversion of the magnetic data to the geomagnetic dipole coordinate system is desirable to discuss precisely the geomagnetic phenomena. In this section, all the data are converted to the geomagnetic dipole coordinate system, using the declination angle obtained by absolute measurements and the calculated azimuthal angle of the geomagnetic dipole meridian at each station. Therefore, $H$ and $D$ components in this section mean northward and eastward components in the geomagnetic dipole coordinate system.

The latitudinal variations in SC amplitudes of $H$ and $D$ component observed in Japanese routine observatories, 


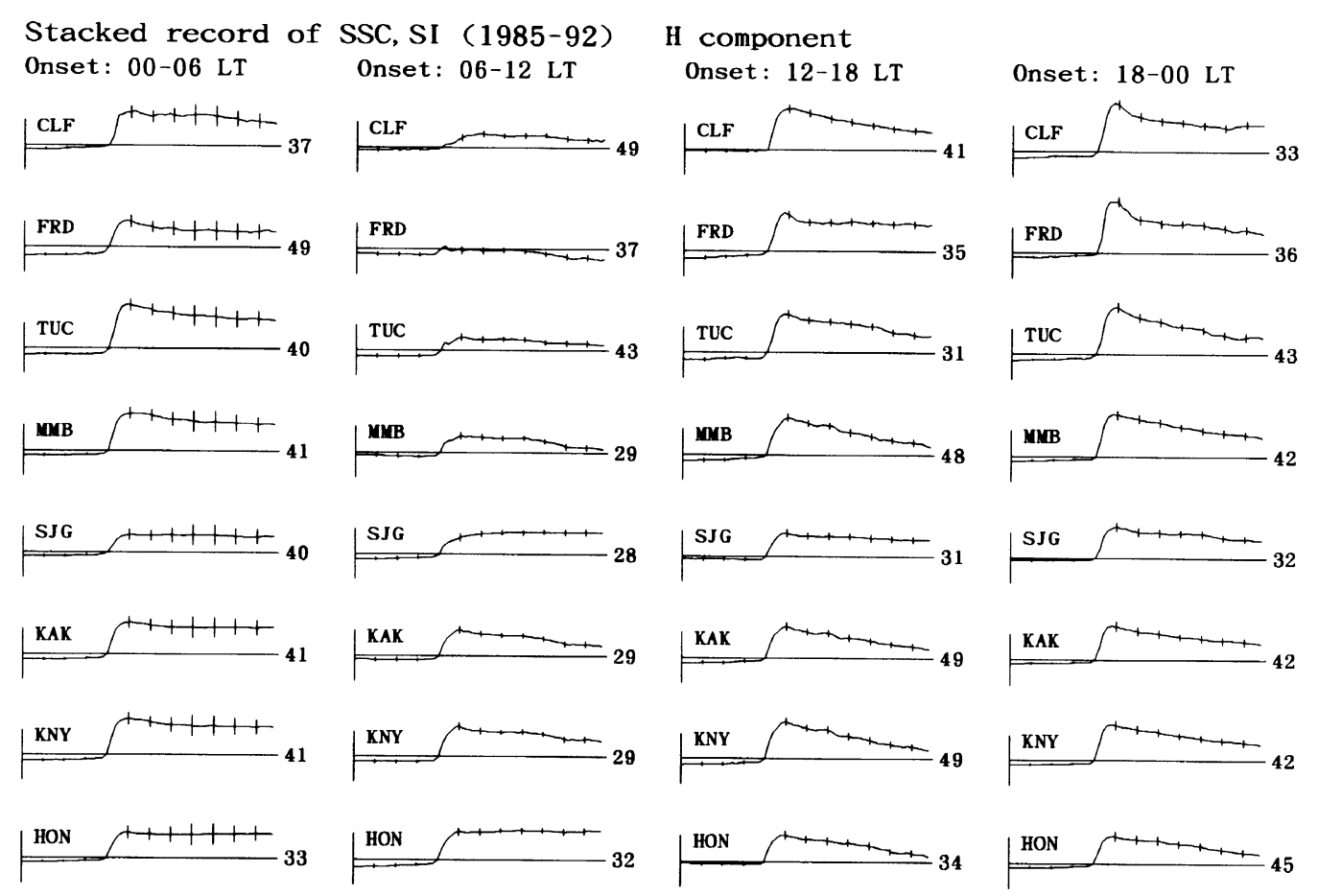

Bar length $=1$ hour $(x), 40 \mathrm{nT}(\mathrm{y})$

Fig. 5(a). Average variation of $H$ component for SC's from 1985 to 1992 at CLF, FRD, TUC, MMB, SJG, KAK, KNY and HON for the four local time blocks at each station. The length of the each graph is one hour in time and the length of the bar at the left corresponds to $40 \mathrm{nT}$ magnetic variation. The onset of SC is arranged at twenty minutes after the start of each graph. The bars on the graphs denote standard errors.

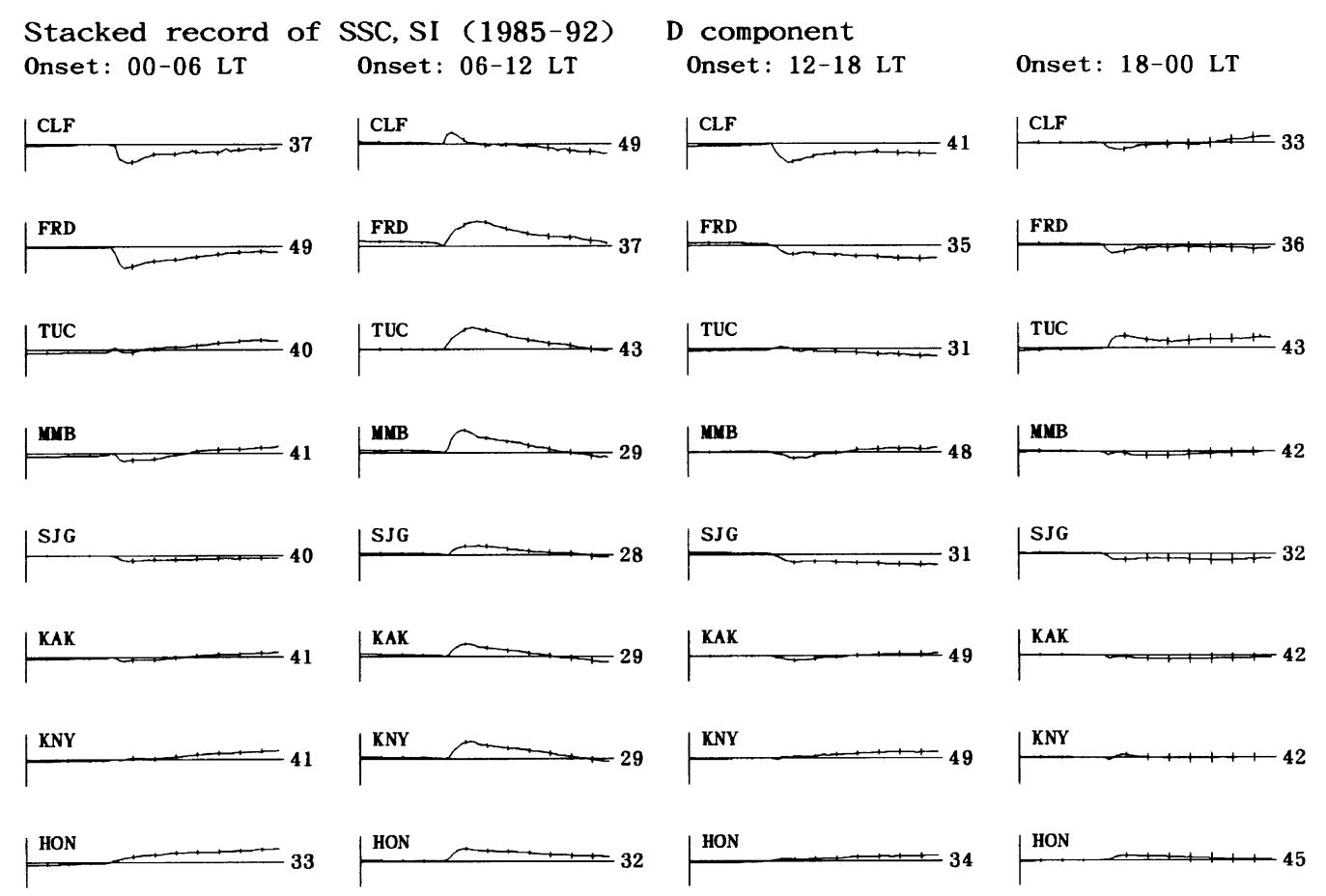

Bar length $=1 \operatorname{hour}(x), 40 \mathrm{nT}(\mathrm{y})$

Fig. 5(b). Same as Fig. 5(a) for $D$ component. 
SSC, SI at MMB and FRD Bar length $=1$ hour $(x), 40 \mathrm{nT}(\mathrm{y})$

H comp
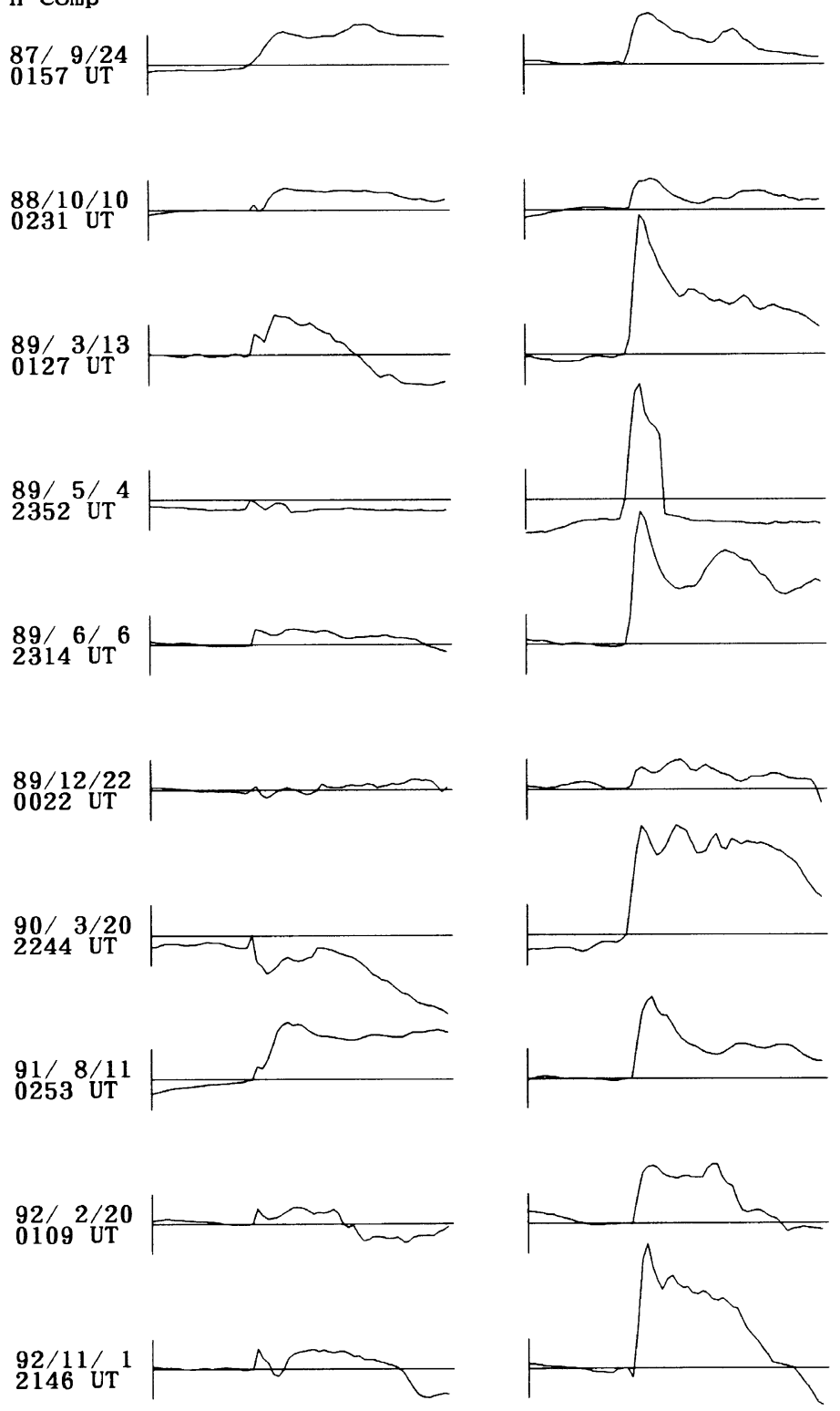

Fig. 6(a). Magnetic variations observed simultaneously at MMB (left) and FRD (right) for SC events when MMB is in the morning hours.

MMB, KAK, KNY and CBI are shown in Fig. 2. As these observatories are situated in nearly same magnetic meridian, the data are shown in the order of the magnetic latitude. The value of each point is the average of the normalized SC amplitude at each station to that at MMB, that is, the average of the linear regression coefficients of ten samples of oneminute magnetic data just after the onset of SC at the station to those at MMB. The results are displayed for four local time intervals. The tendency that the amplitudes are larger in higher latitude than in lower latitude is clear in $D$ component for all local time blocks. For $H$ component, the gradient of the latitudinal variation becomes gentler than $D$ component except for the 06-12 LT block where the tendency is reversed.

It is expected that the DL field, being caused by the increase of the magnetopause current, produces the northward magnetic field in the geomagnetic dipole coordinate system and that the $\mathrm{DP}_{\mathrm{MI}}$ is responsible for the remaining complicated distribution of the magnetic fields of MI (Araki, 1994). The difference in the gradient between $H$ and $D$ components is due to this mechanism that $H$ component is basically the superposition of $\mathrm{DL}$ and $\mathrm{DP}_{\mathrm{MI}}$ fields whereas $D$ component is basically made by $\mathrm{DP}_{\mathrm{MI}}$ field. Similar difference in the latitudinal profiles between $H$ and $D$ components was also seen in the analysis of Pi2 magnetic pulsation (Yumoto et al., 1994, 1995). It is thought that the amplitudes are enhanced a little due to the ground induction effects at MMB and KNY as noted by Tsunomura (1995).

Figures 3(a) and (b) are the scatter plots of the amplitude ratio for each event. Closed square is for the ratio of SC amplitude at KAK to that at MMB and open one for that of 
H comp
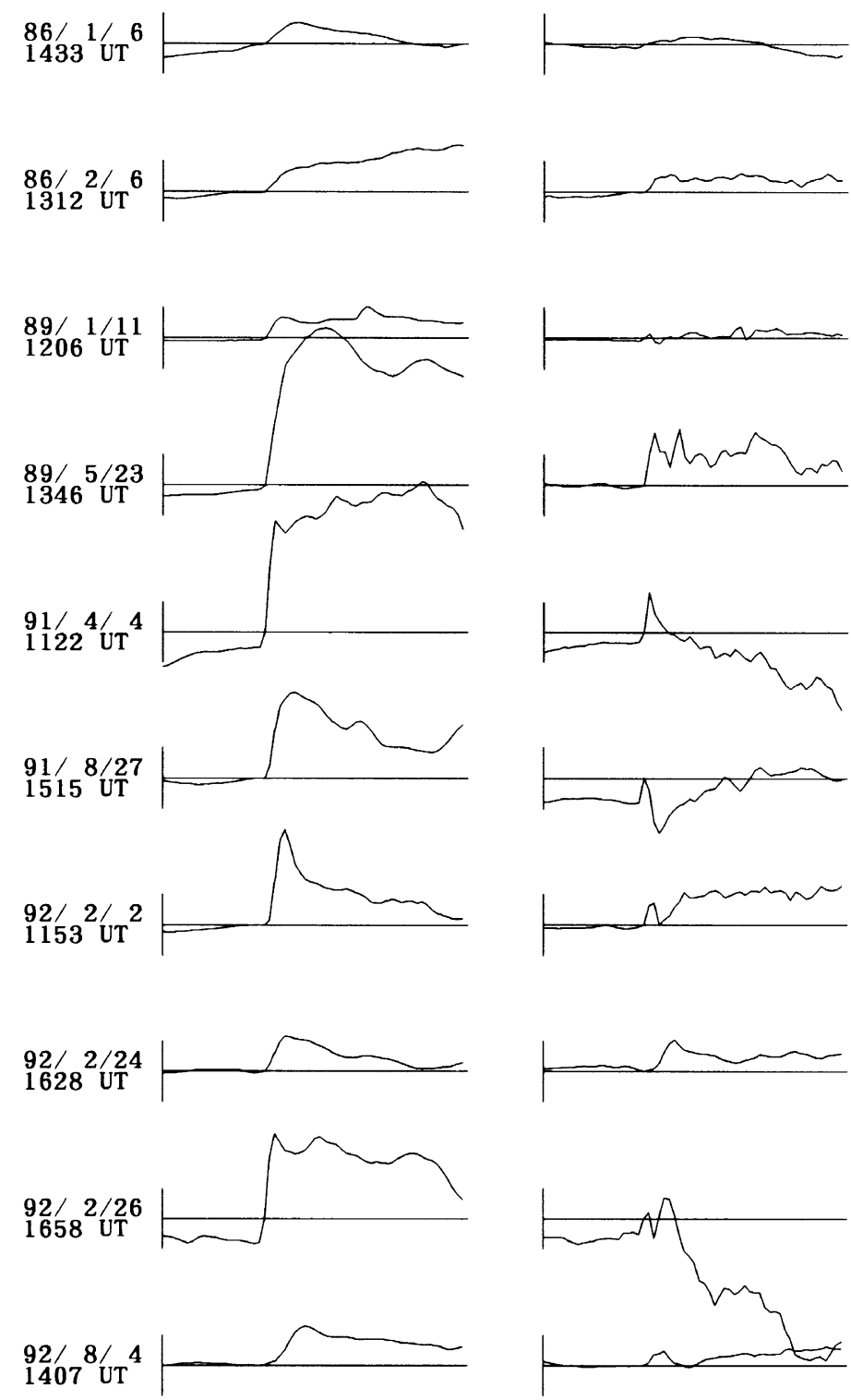

Fig. 6(b). Same as Fig. 6(a) for the SC events when FRD is in the morning hours.

KNY to MMB. The amplitude ratio reveals characteristic change in $H$ component in the morning hours near 08 to 10 LT. Such a variation pattern is not seen in $D$ component. The dependence of the SC amplitude ratio of KAK to MMB in local time from $03 \mathrm{LT}$ to $13 \mathrm{LT}$ on geomagnetic disturbance is shown in Fig. 4. Here, $A p$ index before the onset of SC is used as the parameter of the magnetic disturbance. Any clear relationship between the amplitude ratio and $A p$ index is not seen from the figure. The situation is same for the result when the $A p$ index after the $\mathrm{SC}$ is used. It is inferred that the anomalous amplitude ratio seen in $H$ component in the morning hours is not related with geomagnetic activity before and after the SC.

To discuss the local time variation of $H$ component of SC in another aspect, variation patterns of SC in the four local time blocks same as Fig. 2 are examined by a superposed epoch analysis of one-minute magnetic data at CLF, FRD, TUC, MMB, SJG, KAK, KNY and HON. The results are shown in Figs. 5(a) and (b), where the data are displayed from high to low geomagnetic latitudes. The averaging method is same as Tsunomura (1995); the magnetic data are converted to the geomagnetic dipole coordinate system at first and then averaged after arranging to the onset time of SC detected at KAK. The onset of SC is arranged at 20 minutes after the start of each graph and the bars on each graph are the standard errors.

It can be seen that $H$ component in the morning hours show irregular forms of variation at stations in higher latitude among the stations in the figure, such as CLF and FRD; the variation form becomes flat resulting in the reduction of the 


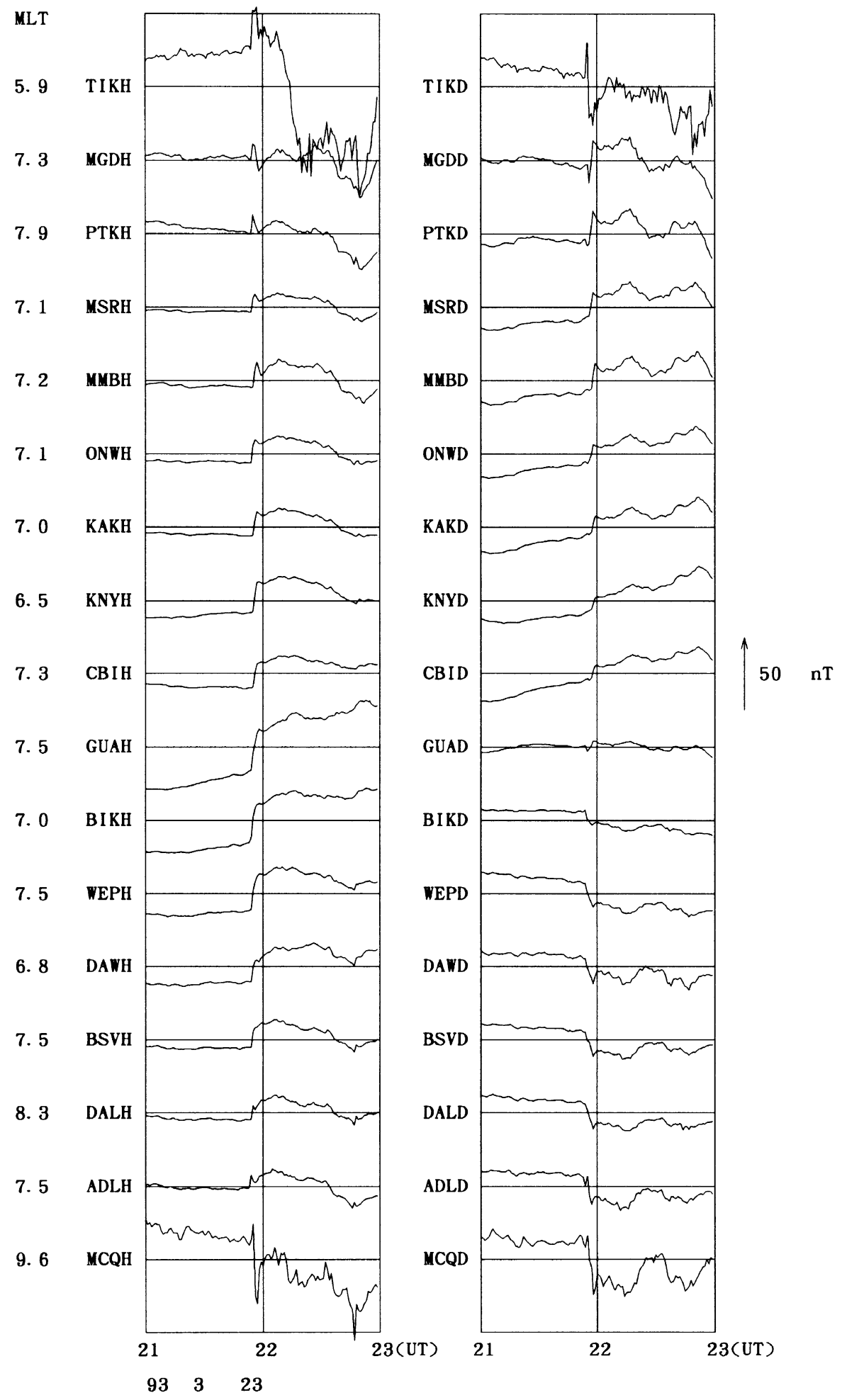

Fig. 7(a). Correlation plot of $H$ or $X$ (left) and $D$ or $Y$ (right) components of magnetic records for the 1993 Mar. 23 SC event around the $210^{\circ}$ magnetic meridian. MLT at each station is noted leftmost.

amplitude. This feature would be related with the statistical result given by Russell and Ginskey (1995) for the subauroral stations. They showed that $H$ component shows definite depression in the morning hours in the magnetic stations located from $54^{\circ}$ to $58^{\circ}$ geomagnetic latitudes. It seems that a negative pulse is superposed on the main impulse at FRD, TUC and MMB in the 06-12 LT block. At CLF, although it is not clear whether a negative impulse is superposed or not, the amplitude of SC is depressed. The deformation of this type is seen in the variation form of the SC in the afternoon side as Tsunomura (1995) showed (figure 6 of Tsunomura (1995)). Note that the variation forms in $H$ component in the 18-00 LT block show positive pulse-like structure especially at CLF, FRD and TUC. 


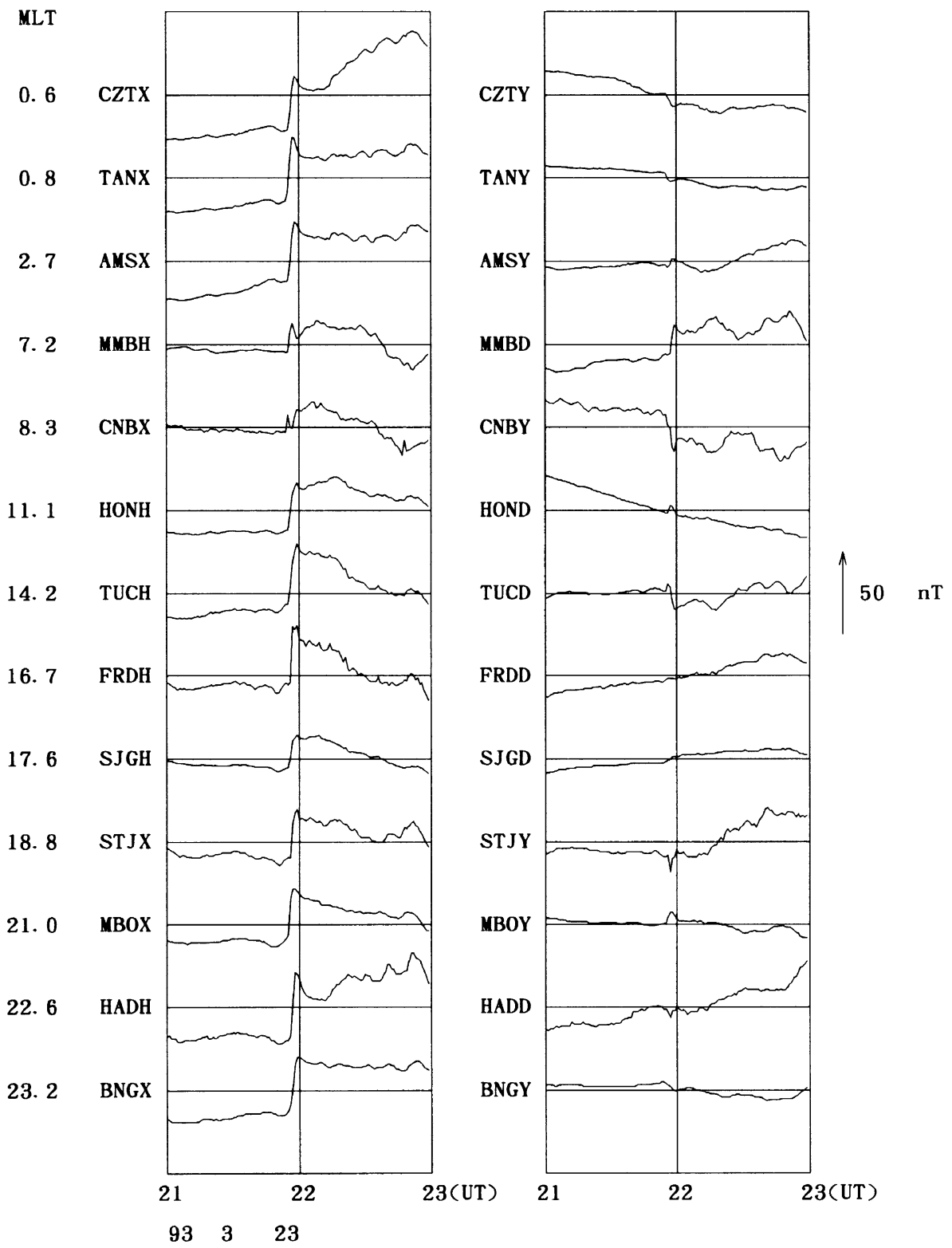

Fig. 7(b). Same as Fig. 7(a) for the routine stations in low to middle latitudes.

Figures 6(a) and (b) are the correlation plot of MMB and FRD for SC's simultaneously observed at both stations. Figure 6(a) is for the events when MMB is in near 06 to $12 \mathrm{LT}$ (that corresponds to near 16 to 22 LT at FRD) and (b) for the events when FRD is in near 06 to 12 LT (that corresponds to near 20 to $02 \mathrm{LT}$ at $\mathrm{MMB}$ ). It can be seen that the variation patterns are quite different for both stations. The amplitude of the magnetic variation at the observatory in the morning is in general much smaller than that at the observatory in the evening to midnight; moreover, in some events negative variations are observed in the morning. In most cases, a negative impulse is superposed on the MI of SC in the former. The period of the negative impulse seems to be different for each event.

It is imagined that a negative impulse is usually accompanied with the MI of SC and contributes the decrease of the SC amplitude in $H$ component at the stations from subau- roral region to middle latitudes in the morning hours. If the superposing negative impulse is originated in high latitudes and is weakened with decreasing latitude, the apparent amplitude ratio of SC in $H$ component in lower latitude to that in higher latitude would become high. It is interesting that the variation pattern of the SC in the morning hours discussed here is similar to that of PPI (Kikuchi and Araki, 1985). The local time range when this pattern is seen is nearly the same as that of the frequent occurrence of PPI shown by Kikuchi and Araki (1985). In the next section, characteristics of this negative impulse will be investigated on the basis of a case study and a numerical analysis.

\section{Case Study and Numerical Analysis}

Magnetic records for the SC on March 23, 1993 around $210^{\circ}$ magnetic meridian are shown in Fig. 7(a). Since the absolute measurements are not operated at some of the sta- 

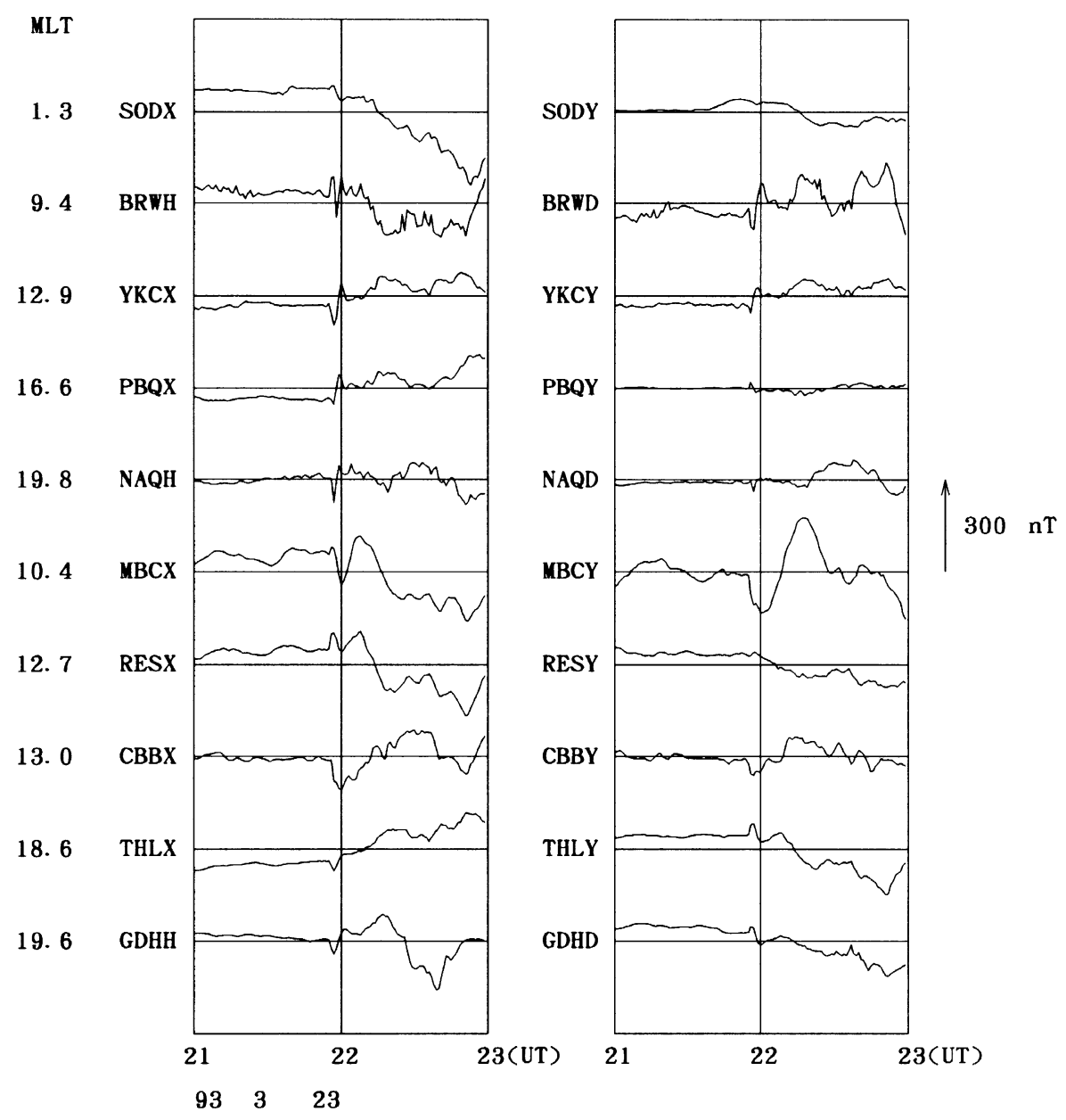

Fig. 7(c). Same as Fig. 7(a) for the routine stations in the auroral region (upper five) and the polar cap (lower five).

tions of the $210^{\circ}$ magnetic meridian observatory network, the data shown in Figs. 7(a)-(c) are not the ones converted to the geomagnetic dipole coordinate system. It can be seen that a negative impulse the duration of which is about ten minutes is superposed just after the onset of SC at high and middle latitude stations. The amplitude of the negative impulse is highest at the station at the highest latitude in both hemispheres (MGD and ADL) and decays rapidly with decreasing latitude. Hence, it is expected that the negative impulse was originated in high latitude. Negative impulse is not seen in $D$ component but it seems that $D$ component itself is anticorrelated with the negative impulse of $H$ component. From another point of view, the $H$ component variation accompanied with a negative impulse seen at high and middle latitude stations may be noted as PPI according to the criterion of Kikuchi and Araki (1985). A substorm occurs about twenty minutes after the SC at TIK, being clearly after the occurrence of the negative impulse. PRI was seen in $D$ component at TIK, MGD, PTK, ADL and MCQ. The duration times of them are definitely different from those of the negative impulses in $H$ component. Therefore, it is deduced that the negative impulse is different from PRI. It is noteworthy that Kikuchi and Araki (1985) also mentioned that PPI and PRI are different phenomena.

Data at various local times in low to middle latitudes are shown in Fig. 7(b) and those in high latitudes in Fig. 7(c), respectively. The upper half of Fig. 7(c) is for the stations in the auroral region and lower for those in the polar cap. The negative impulse is seen only for MMB and CNB in Fig. 7(b); these stations are in the morning hours at the time. The duration time and the variation form of the negative impulse are similar with $H$ component at MBC and RES and $D$ component at THL and GDH in Fig. 7(c). From this fact it is expected that the phenomenon is not a localized event in a limited area and that it is a signature of a global process.

Figure 8 is the equivalent current vectors for the magnetic variations at the time of the negative impulse; the vectors are drawn for all the available stations in Fig. 1. The equivalent currents are derived for the time changes of the magnetic variations corresponding to the negative impulse seen in the $210^{\circ}$ magnetic meridian chain; the time interval to derive the currents is denoted in the figure. In the figure, a counterclockwise vortex in the afternoon side can be seen, whereas the pattern is not clear in the morning side. The ionospheric current system for $\mathrm{DP}_{\mathrm{MI}}$ is thought to consist of twin vortices in these region, one is counterclockwise in the afternoon side and the other clockwise in the morning side. The eastward equivalent current due to DL field may affect the ambiguity of the current pattern in the morning side. A distinctive de- 


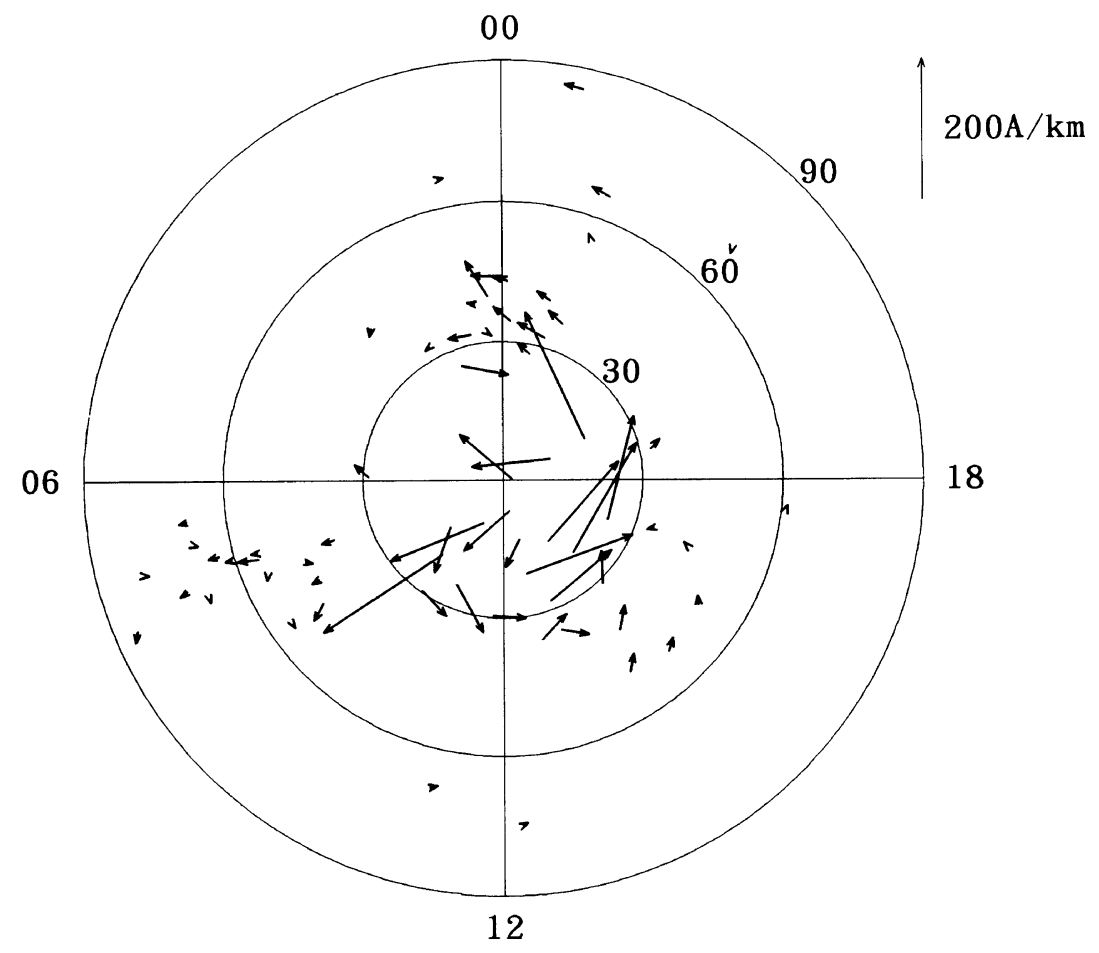

$1993 / 03 / 23 \quad 2157-2159$ UT

Fig. 8. Equivalent current vectors for the SC event on 1993 Mar. 23.

formation of the current system from that of the $\mathrm{DP}_{\mathrm{MI}}$ field cannot be found from the figure. Therefore, the pattern of the current system may reveal the nature of development of $\mathrm{DP}_{\mathrm{MI}}$. From these results, a possibility can be introduced that the global scale process associated with the negative impulse is the MI of SC itself.

Hence, the negative impulse seen in $H$ component in middle and low latitudes in the morning hours cannot be judged as a newly found phenomenon but is most likely the signature of $\mathrm{DP}_{\mathrm{MI}}$ in that area. This interpretation can explain the resemblance of $D$ component with the negative impulse in $H$ component as can be seen in Fig. 7(a) and the scattering in its period seen in Figs. 6(a) and (b). Now I would like to examine a possibility that $\mathrm{DP}_{\mathrm{MI}}$ field itself can produce such variation patterns by a model calculation.

The $\mathrm{DP}_{\mathrm{MI}}$ is basically driven by an electric field originated in the polar region. The field is transmitted from the outer magnetosphere through field-aligned currents, which flow into the ionosphere in the morning side and away from the evening side (Araki, 1977, 1994). The ionospheric current system can be calculated on the basis of a steady state current system model with the input source currents in high latitudes and ionospheric conductivity distribution (Kamide and Matsushita, 1979a, b; Tsunomura and Araki, 1984).

The noon-midnight profile of the height-integrated ionospheric conductivity in the polar coordinate system $(\theta, \lambda)$ used in the present calculation is shown in Fig. 9. Here, $\theta$ is colatitude and $\lambda$ longitude. The profile is based on IRI-90 and CIRA-72 models, corresponding to nearly the average solar activity condition (sunspot number $=50$ ) in equinox. A slight enhancement in the auroral region is given using the model of Reiff (1984); AE parameter in the model is set as zero. The form of the input source current is as follows;

$$
j_{\|}= \pm j_{0} \exp \left[-\frac{\left(\theta-\theta_{0}\right)^{2}}{D_{\theta}^{2}}-\frac{\left(\lambda \mp \lambda_{0}\right)^{2}}{D_{\lambda}^{2}}\right],
$$

where the upper and lower signs of $j_{0}$ and $\lambda_{0}$ are taken for the currents flowing into and away from the ionosphere, and positive or negative values of $\lambda$, respectively. The parameters, $\theta_{0}, \lambda_{0}, D_{\theta}, D_{\lambda}$ and $j_{0}$ are set $75^{\circ}, 105^{\circ}$ (for the morning side) and $225^{\circ}$ (for the evening side), $15^{\circ}, 2^{\circ}$, and $10^{-6} \mathrm{~A} / \mathrm{m}^{2}$, respectively. Grid intervals are $1^{\circ}$ for $\theta$ and $7.5^{\circ}$ for $\varphi$. The magnetic variation on the ground is derived on the basis of the equivalent current after adding the effect of field-aligned current contribution. For the current near the equator, the magnetic variation due to the narrow jet current is calculated by Biot-Savart's law for the currents in the range of $5^{\circ}$ north and south.

Local time variations of $H$ and $D$ components at 50,30 and $5^{\circ}$ latitudes derived by the calculation are shown in Fig. 10. Negative variations are seen in $H$ component in the morning hours in middle latitudes $\left(50^{\circ}\right)$ but not large in low latitudes $\left(30^{\circ}\right)$. The variations of the signs of $D$ component are similar to the results in Fig. 5(b). Note that the calculated variations should be superposed on the DL field for $H$ component, which is expected to show gradual variations in both of latitudinal and local time distributions comparing with those of $\mathrm{DP}_{\mathrm{MI}}$ field. In Fig. 10, $D$ component in the morning hours does not seem to decrease its amplitude with decreasing latitude not so fast as $H$ component in that local time range. This result agrees well with the fact that the amplitude of the negative impulse in $H$ component decreases faster with 


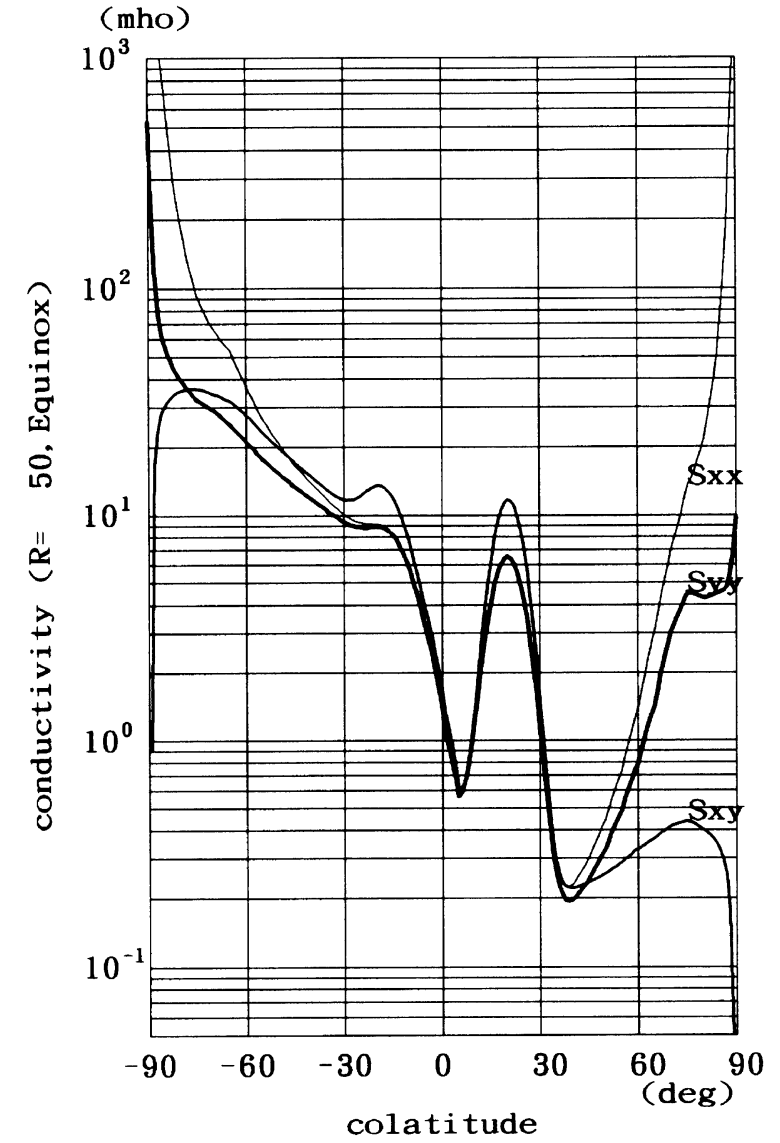

Fig. 9. Noon-midnight profile of ionospheric height-integrated conductivity $\Sigma_{\theta \theta}\left(S_{x x}\right), \Sigma_{\theta \varphi}\left(S_{x y}\right)$ and $\Sigma_{\varphi \varphi}\left(S_{y y}\right)$ of the condition of equinox and sunspot number $=50$ for IRI parameters. The left side is noon and the right one is night.

decreasing latitude than the MI of $D$ component as seen in Fig. 7(a).

It is worth to note that the variation of $H$ component is positive and large in the nighttime. The ionospheric current contributions are negative but small in the nighttime at these latitudes. Most of the positive variation in this local time range is the product of the field-aligned current effects. The variation forms observed in these local time ranges show usually positive pulse-like structures in $H$ component (Figs. 5(a), 6(a) and (b)). Yamada et al. (1997) showed that the average polarity of PRI in the night in middle latitudes is negative. This corresponds to the positive MI in that local time range and is consistent with the present result.

Now a self-consistent interpretation on the basis of the existing model is suggested for the local time variation pattern of the MI of SC. It is added that the signs of calculated $\mathrm{DP}_{\mathrm{MI}}$ fields are almost the same as the remaining part of the ground magnetic variations for the CME event of February 21, 1994 after subtracting the magnetopause current contribution as shown by Petrinec et al. (1996).

Latitudinal variations of $H$ and $D$ components derived by the calculation are shown in Fig. 11. All components decrease their amplitude almost monotonously with decreasing latitude. $H$ component in the morning hours (06-12 LT block) is negative in middle to low latitudes and grows up large positive value near the equator. Superposing this simply on the DL, it can be expected that the amplitude of $H$ component in this local time range shows the profile shown in Fig. 2. Actually, since the variation forms of DL and DP are possibly different, the complicated profiles such as the discrepancy of the ratio of the amplitude at KAK to MMB seen in the morning hours (Fig. 3(a)) may be apparent. The equivalent current vectors mapped in the geomagnetic polar coordinate system are shown in Fig. 12. The gross distribution pattern of the currents is basically the same as those shown in Fig. 8. With these results, it is shown that the negative impulse in $H$ component in the morning hours in middle and low latitudes can be produced by a model calculation based on the model of the $\mathrm{DP}_{\mathrm{MI}}$ given by Araki (1977).

\section{Discussion}

\subsection{Negative impulse and PPI}

In the foregoing sections, it is shown that a negative impulse is usually superposed on the MI of SC in $H$ component at the stations from high to low latitudes in the morning hours and is suggested that it is the signature of $\mathrm{DP}_{\mathrm{MI}}$ field in this area. The latitudinal and/or local time profiles of the magnetic field obtained by a model calculation agree well with the observed features of the negative impulse. It must be noted that the profiles of the magnetic variations in middle latitude are not changed so much if the conductivity model without the equatorial enhancement is used for the calculation. I checked it by a similar calculation setting the conductivity values in low latitudes equal from $30^{\circ}$ latitude to the equator. The gross pattern of the ionospheric current system is basically controlled by the condition of the conductivity from high to middle latitudes.

A substorm is often triggered by SC (Kokubun et al., 1977; Iyemori and Tsunomura, 1983). The occurrence of a substorm may accompany additional current systems such as a wedge current and/or the enhanced DP2 type ionospheric current system. There may be a possibility that the negative impulse discussed in the previous sections is caused by these current systems. However, the duration time of the impulse is basically much less than that of a typical substorm and the corresponding substorm is not seen in the case study in the previous section. As shown in Fig. 4, the SC amplitude ratio of KAK to MMB does not depend on geomagnetic disturbance before and after the SC. If the negative impulse is caused by the SC-triggered substorm, it should show the dependence on geomagnetic activity. Therefore, it is thought that the negative impulse is not a signature of the SC-triggered substorm.

Kikuchi and Araki (1985) showed that a positive impulse often precedes the MI of SC and named it PPI. The variation pattern and the dependence of occurrence frequency on local time are same as the negative impulse discussed here. They suggested that the positive impulse is the magnetospheric compression effect after examining the HF Doppler observation associated with PPI. However, the westward electric field to which they mentioned that PPI corresponds can be explained also as the electric field of $\mathrm{DP}_{\mathrm{PRI}}$. From this point of view, the PPI is the apparent positive variation visualized by the succeeding negative impulse. The superposition of the 

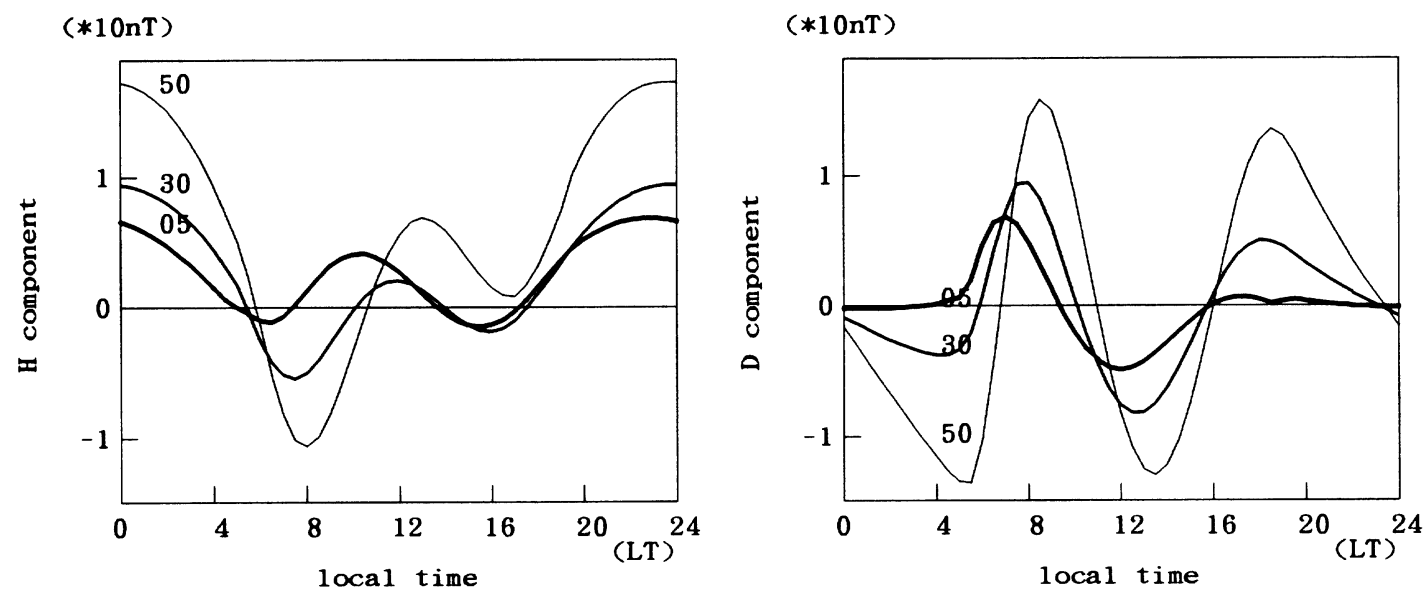

Fig. 10. Local time variations of $H$ (left) and $D$ (right) components of magnetic variations at $05^{\circ}$ (thick), $30^{\circ}$ (medium) and $50^{\circ}$ (thin) latitudes.
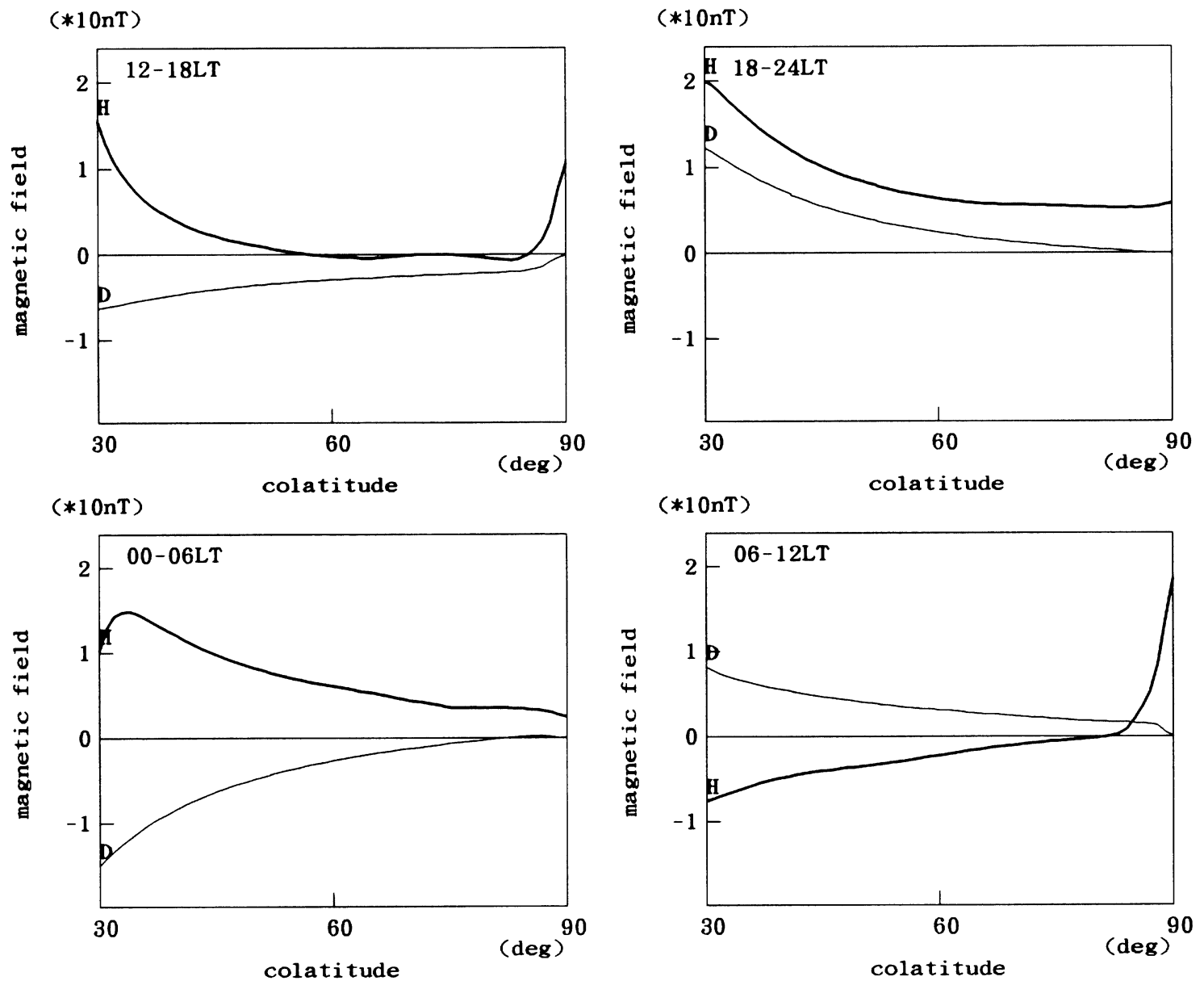

Fig. 11. Average latitudinal variations of $H$ (solid) and $D$ (thin) components of magnetic variations from $60^{\circ}$ to $0^{\circ}$ latitude for four local time blocks.

DL and DP ${ }_{\mathrm{PRI}}$ fields, giving rise to the sharp onset signature, promotes the apparent positive variation.

The fact that the PPI at GUA was not much larger than that at MMB (Kikuchi and Araki, 1985) is also explained as follows. As PPI amplitude is basically small and over- lapped to DL field, the exact amplitude estimation is difficult primarily. Moreover, the result of this paper shows that the magnetic field would not reveal large enhancement at $5^{\circ}$ latitude (Fig. 10). The amplitude grows up rapidly with decreasing latitude towards the equator. The observational 


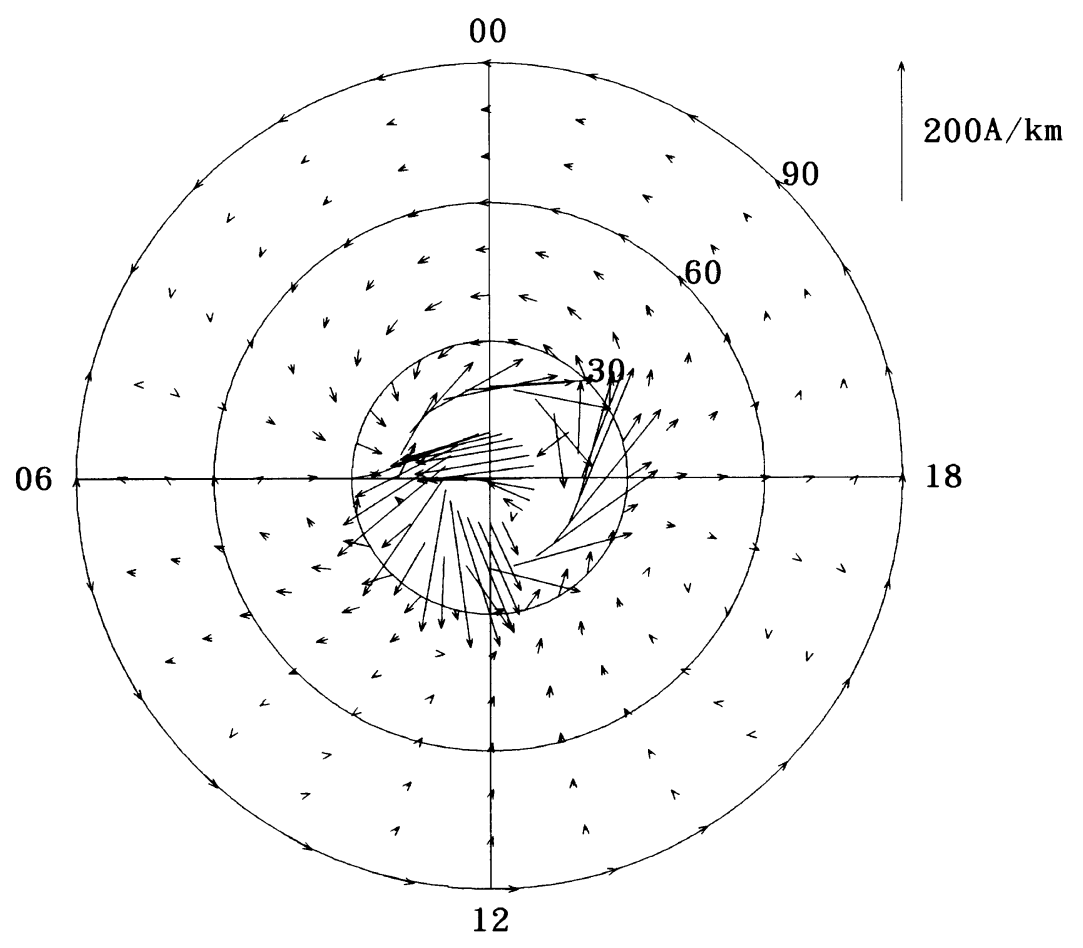

Fig. 12. Equivalent current vectors.

fact of Kikuchi and Araki (1985) is not contrary to the DP field model. Hence, it is suggested that PPI is the apparent magnetic variation due to the pair of positive variation made by $\mathrm{DL}$ and $\mathrm{DP}_{\mathrm{PRI}}$ fields and the succeeding negative impulse due to $\mathrm{DP}_{\mathrm{MI}}$. The pattern is a basic signature of $\mathrm{DP}_{\mathrm{PRI}}$ and $\mathrm{DP}_{\mathrm{MI}}$ in middle to low latitudes. This interpretation for the observed magnetic variation is illustrated in Fig. 13.

Yamada et al. (1997) showed that PRI is often positive in the morning hours in middle latitudes. According to the classification of their positive PRI (figure 1 of Yamada et al. (1997)), it can be said that their positive judgement corresponds to PPI or MI with a negative impulse discussed above. Occurrence frequency of the positive PRI mentioned by Yamada et al. (1997) is almost identical with that of the negative impulse discussed here.

There is an observational result that the $H$ component in the daytime is a little smaller for the southward IMF- $B z$ condition than that for the northward condition (Russell et al., 1994a, b). This can be interpreted that $\mathrm{DP}_{\mathrm{MI}}$ field is larger for the southward IMF- $B z$ than the northward for the same dynamic pressure change. If the $\mathrm{DP}_{\mathrm{MI}}$ field becomes stronger the morning side depression becomes large as shown above. From this point of view, DL and $\mathrm{DP}_{\mathrm{MI}}$ fields should be related with different solar wind parameters respectively. This is partly confirmed that $D$ component variation due to sudden solar wind dynamic pressure change is not correlated with the dynamic pressure change of the solar wind as shown by Sitar et al. (1996). They discussed the matter on the basis of the magnetic variation due to the field-aligned current without including the ionospheric current effects. Taking into account of the ionospheric current effects, the pattern may be explained more clearly.

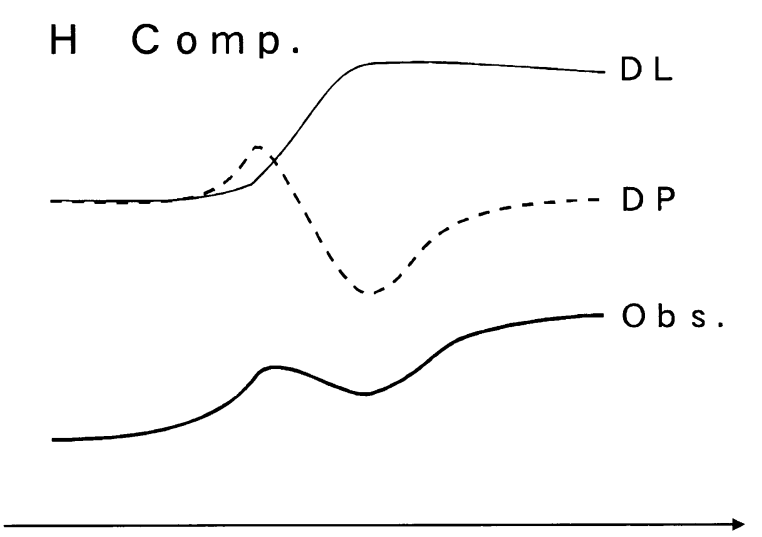

$\mathrm{T}$ i m e

Fig. 13. An illustration for the interpretation of PPI.

As one of the most pronounced events of SC, that of 1991 Mar. 240341 UT is object of interest of many authors. Araki et al. (1997) analyzed the event using many kinds of data and explained it by the existing models of SC successfully. For the extraordinary variation of the $D$ component, Araki et al. (1997) tried to explain by the observational situation of the routine measurement. They mentioned that $D$ component data include the projection of $H$ component because of the orientation of magnetometers to the local declination direction, which is for most cases different from the direction of the geomagnetic dipole magnetic meridian.

To examine the validity of their explanation, I tried the actual conversion of the magnetic data in this event to the geomagnetic dipole meridian direction. Figure 14 shows the 

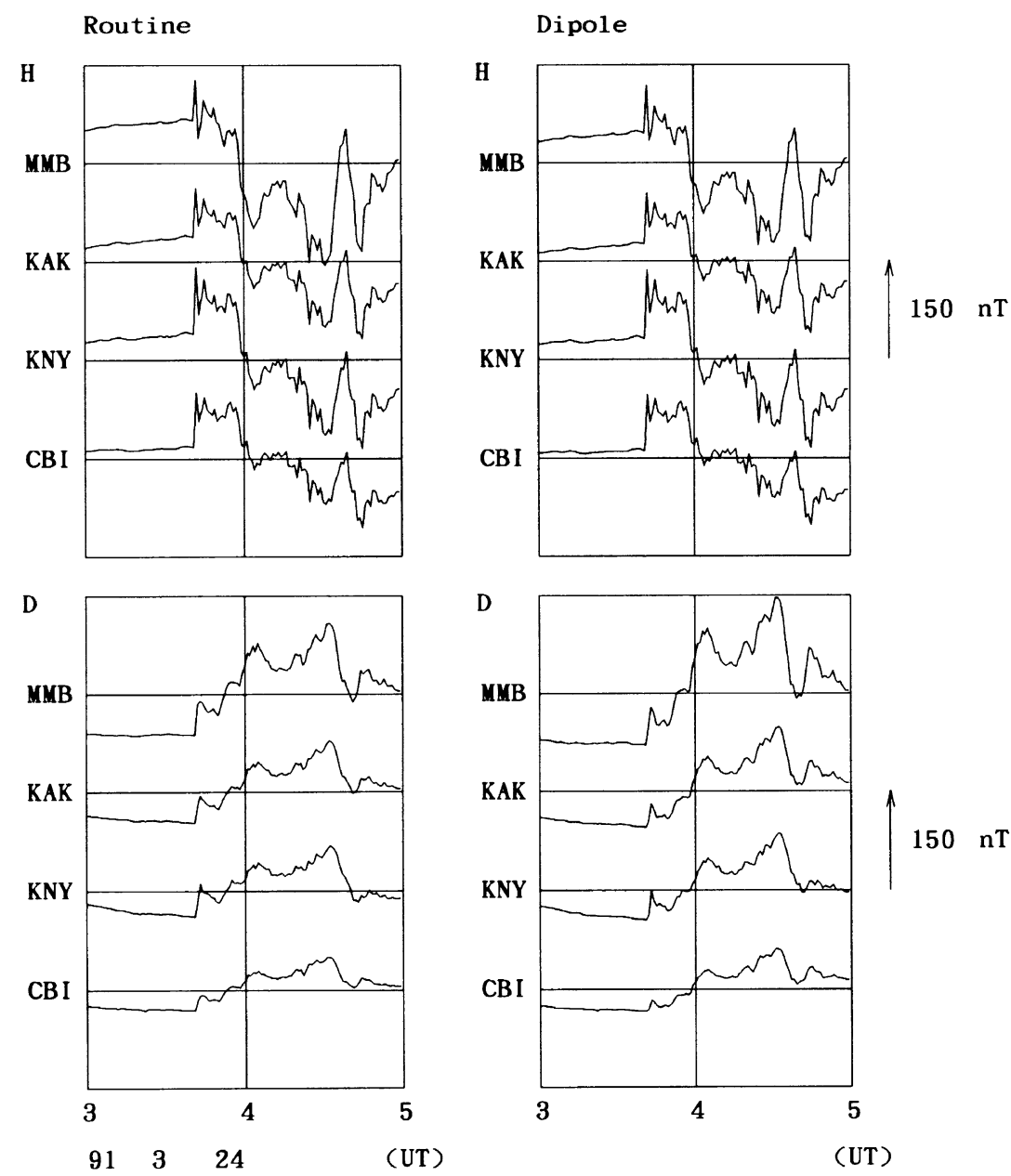

Fig. 14. Correlation plot of $H$ (upper panels) and $D$ (lower panels) components of magnetic records at Japanese routine stations for 1991 Mar. 24 SC event. The left panels are the routine data and the right ones are those converted to the geomagnetic dipole coordinated system.

results at $\mathrm{MMB}, \mathrm{KAK}, \mathrm{KNY}$ and $\mathrm{CBI}$; these stations were near the local noon at this event. It is obvious that most of $D$ component variation remains after the conversion even the variation form becomes a little sharp. Therefore, the variation pattern of $D$ component at these stations is not explained sufficiently by their interpretation. They might overestimate the strength of the DL field and thus underestimate that of the $\mathrm{DP}_{\mathrm{MI}}$. I would like to try to explain the variation pattern considering the negative impulse discussed in this paper.

At the time of 0341 UT, Japanese stations are near the noon. As can be seen from Fig. 10, the calculated $D$ component near 12 LT is small or negative; that is different from the observation. The observed $H$ component shows a pair of a sharp increase and a rapid decrease at KAK. According to the previous discussions, the rapid decrease would be the signature of $\mathrm{DP}_{\mathrm{MI}}$, whereas the calculated $H$ component of $\mathrm{DP}_{\mathrm{MI}}$ is small or rather positive as shown in Fig. 10. A modification of the calculation is necessary to explain the observational features in this event.

There is a report that the corresponding solar wind shock attacks the magnetosphere from the evening side (Blake et al., 1992) at this event. That may cause the azimuthal shift of the source current distribution. According to the discussion of Blake et al. (1992), I calculated the ionospheric current with the source current shifted such as to make the center at 1600 LT. Figure 15 shows the local time variations of the magnetic field as in Fig. 10 but with the center being shifted. The sufficient negative variation is expected at the noon and $D$ component is positive at middle latitudes. The east-west component of the electric field in middle latitudes obtained from the model is eastward (not shown here). This agrees well with the observed feature of HF Doppler frequency variation (figure 4 of Araki et al. (1997)). Thus, the variation pattern of Mar. 24, 1991 event can be explained by azimuthally shifting the position of the origin of $\mathrm{DP}_{\mathrm{MI}}$ field.

\subsection{Significance of $\boldsymbol{D}$ component}

It is established that the DL field has the direct correspondence with the solar wind dynamic pressure change, whereas the origin of the $\mathrm{DP}_{\mathrm{MI}}$ has not been exactly clarified. Although the pattern of the equivalent current system of the $\mathrm{MI}$ is the same as that of the ionospheric convection currents, the whole magnetospheric convection may be difficult to develop sufficiently in a short time range of SC duration (Kikuchi, 1986). As Kikuchi (1986) pointed out, the current system may develop due to a process at the outmost side of the magnetopause. As the origin of the field may be related to the solar wind electric field variation, an investigation to examine the relationships between the time variations of the 

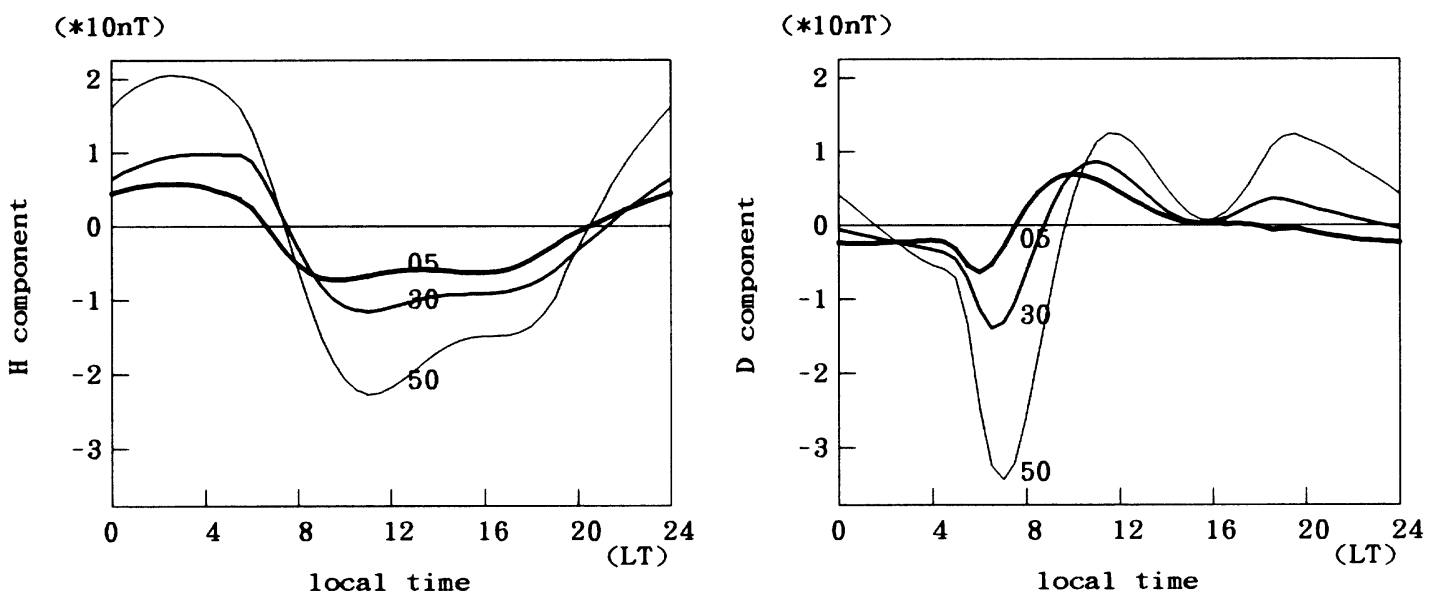

Fig. 15. Local time variations of $H$ (left) and $D$ (right) components of magnetic variations at $05^{\circ}$ (thick), $30^{\circ}$ (medium) and $50^{\circ}$ (thin) latitudes given by the model calculation shifting the source currents to the evening side.

Q-Day mean removed stack of SSC (1976-92) at KAK (Dipole frame)

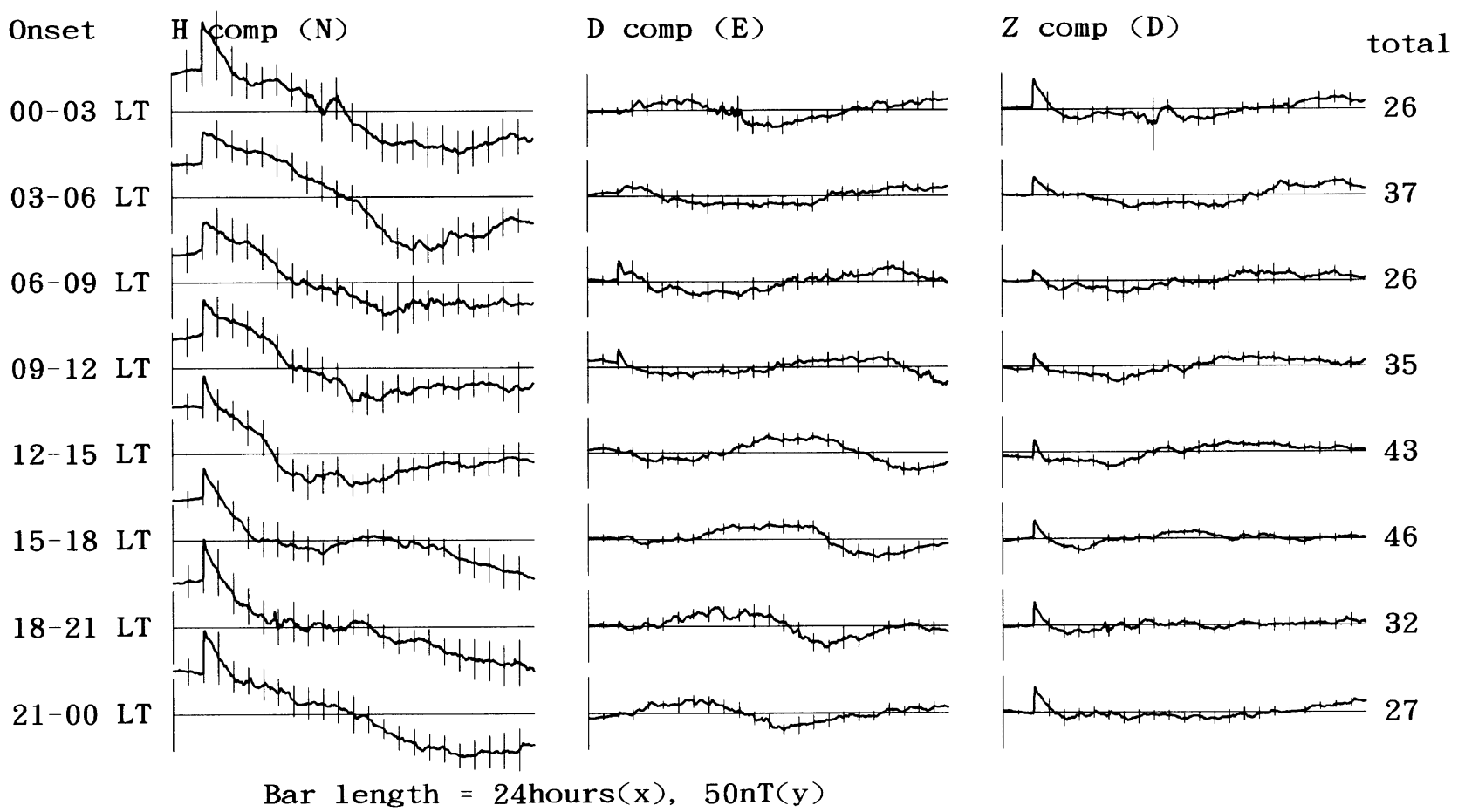

Fig. 16. Average magnetic variations of geomagnetic storms started with SC in eight local time ranges at Kakioka from 1976 to 1992 . The number in the right is that of the events to take the average. The bars on each graph denote standard errors.

solar wind electric field and the $\mathrm{DP}_{\mathrm{MI}}$ field is necessary at least to fully understand the matter.

Although the $H$ component variation usually shows a step like variation corresponding well to the solar wind dynamic pressure, it cannot be used as a parameter for $\mathrm{DP}_{\mathrm{MI}}$ field. As shown in the previous sections, it is hard to find out the signature of $\mathrm{DP}_{\mathrm{MI}}$ field from the $H$ component observation. For that purpose, it is suggested that the variation of $D$ component in the morning hours is a candidate as a useful tool.
In this subsection, I would like to present a speculation for the availability of $D$ component as a rough indicator of $\mathrm{DP}_{\mathrm{MI}}$ field.

To see the variation forms of SC in another point of view, stacked records of geomagnetic storms starting with an SC at Kakioka are shown in Fig. 16. Each graph is a stacked record of each component of one-minute magnetic data for geomagnetic storms starting with the SC at Kakioka at the local time range denoted in the leftmost. Original data are 


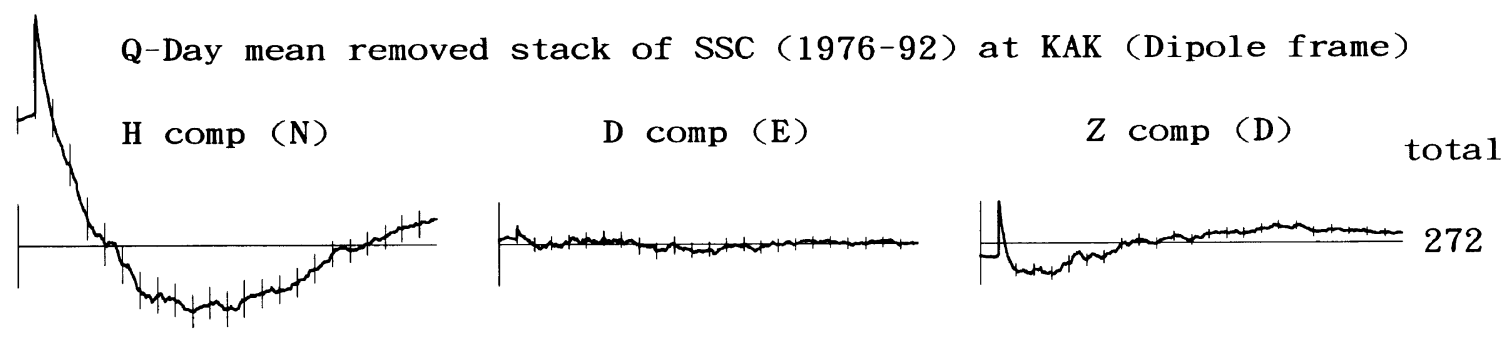

Bar length $=48 \operatorname{hours}(x), 20 \mathrm{nT}(\mathrm{y})$

Fig. 17. The average magnetic variation of geomagnetic storms started with SC at Kakioka from 1976 to 1992 . The length of the each graph is 48 hours in time and the length of the bar at the left corresponds to $20 \mathrm{nT}$ magnetic variation. The number in the right is that of the events to take the average. The bars on each graph denote standard errors.

converted to the geomagnetic dipole coordinate system at first. Then the mean monthly average of the international five quiet days is subtracted to remove the solar diurnal variation pattern. The time span and the sensitivity of the graph are one day and denoted by the bar (50 nT) at the left, respectively. The number in the rightmost is that of the events stacked.

$H$ component shows nearly the same variation forms with a slight difference due to a diurnal pattern, that is, the minimum in the evening and the maximum in the morning. It can be seen a clearer diurnal pattern in $D$ component; the maximum is in the morning and the minimum in the noon hours. These diurnal patterns are thought to be different from those of the solar diurnal variation because they are not apparent before the SC; the patterns are similar to those of the SD fields of geomagnetic storm shown by Sugiura and Chapman (1960). Hence, these are most likely attributed to the field-aligned and the ionospheric current effects during geomagnetically disturbed periods.

The diurnal patterns are vanished for the stacked record of all the events as shown in Fig. 17; the style of the figure is similar to that of Fig. 16 except for the time span and the sensitivity. In the figure, the average pattern of geomagnetic storm at KAK due to the SC and the ring current development is clearly shown in $H$ component. The mean duration of the initial phase duration is nearly one hour but it seems that the ring current develops smoothly just after the SC. Therefore, it is again expected that the various effects are included in the $H$ component during the initial phase. The curve for $D$ component becomes almost flat except for the onset (SC). $Z$ component shows at first the local induction effect as usually seen in the geomagnetic variation at KAK (Tsunomura, 1995). However, $Z$ component about ten hours after the onset shows a different form from the local induction pattern due to conductivity anomaly in the crust; the usual variation pattern of $Z$ component is nearly parallel to $H$ component at KAK. The variation sense of the later part of $Z$ component is positive (downward) and same as the magnetic effect of the ring current. Thus, it is thought that the later part of $Z$ component reveals a signature of the direct contribution of the ring current although most of it is reduced by the ground induction. The degree of the reduction is same as the investigations of the global induction effects (e.g. Rikitake and Sato, 1957) as a rough estimation.
Taking into account of these gross features of geomagnetic storm as a background, I would like to turn the viewpoint to the initial phase. It is noted that $D$ component in 06-09 and $09-12$ LT in Fig. 16 shows clear impulses with somewhat different forms from $H$ component of all the local time blocks. $H$ component, revealing the broader variation form, is the result of superposition of DL and $\mathrm{DP}_{\mathrm{MI}}$ fields. Moreover, $H$ component variation is influenced very much by the succeeding decrease due to the ring current developments as discussed above.

In the previous section it was suggested that the time variation in $D$ component, showing the anti-correlated pattern with respect to the negative impulse of $H$ component, reveals the variation pattern of the $\mathrm{DP}_{\mathrm{MI}}$ field during the initial phase clearer than $H$ component. In reality, SC's in middle to low latitudes in the morning hours show usually large amplitude in $D$ component. Therefore, it is proposed that $D$ component in middle and low latitudes in the morning hours can be used as a measure to estimate the magnetospheric electric field variation of SC. The usefulness as a simple measure may have some reality considering the actual condition that there are limited numbers of magnetic observatories in the world. Here, it is assumed that the polar-originated current system and the field-aligned currents vary simultaneously in parallel.

Similar utilization of $D$ component in the middle latitude in the morning hours to estimate the magnetospheric process may be applied to other phenomena, such as DP2, Pi2 and so on. In the actual discussion, however, it is important to convert the routinely observed $D$ component to the geomagnetic dipole coordinate system in order to exclude the contamination of $H$ component effect as denoted by Tsunomura (1995).

\section{Conclusion}

In this paper, the middle latitude signature of MI of SC is clarified through data analysis and the apparent negative impulse superposed on $H$ component in the morning hours is introduced for the first time. It is proposed that the negative impulse is the signature of $\mathrm{DP}_{\mathrm{MI}}$ field in that area. The possible interpretation for PPI is also given on the basis of this negative impulse.

It is suggested that $D$ component in middle latitudes has a potential to be used as a rough measure to estimate the elec- 
tric field variation due to the whole magnetospheric process. It was mentioned also that the data should be converted to geomagnetic dipole coordinate system to make the analysis more exact. In conversion, the absolute measurements of magnetic fields are necessary to decide the local declination angle. I would like to note that the absolute measurements remain to be important in the future analysis to develop the quantitative analysis in the solar, magnetospheric and ionospheric features.

The result shown here is a statistical feature and the pattern will be different in each event. Case studies to relate $D$ component of SC and/or DP2 observed in middle latitudes with the satellite observations are subjects of future studies.

Acknowledgments. The author would like to appreciate Prof. K. Yumoto of Kyushu University, the PI of the $210^{\circ}$ magnetic meridian network project, for his courtesy of supplying one-minute magnetic data through Solar-Terrestrial Environment Laboratory (STEL) of Nagoya University. The magnetic data in the Siberian region of the $210^{\circ}$ magnetic meridian network were contributed by Prof. E. F. Vershinin of Institute of Cosmophysical Research and Radiowaves Propagation (IKIR) and Prof. S. I. Solovyev of Institute of Cosmophysical Research and Aeronomy (IKFIA) in Russia. The author also acknowledges Prof. T. Araki, Drs. T. Iyemori and M. Takeda of Kyoto University for their encouragement to promote this study and useful discussions. Conductivity model is derived using the computer system of Kyoto University with the aid of Dr. Takeda. The routine observatory data for case studies were copied from the CD-ROMs of INTERMAGNET "Magnetic Observatory Definitive Data", 1993 and those from 1985 to 1992 at CLF, FRD, TUC, SJG, and $\mathrm{HON}$ were supplied from WDC-C2 for Geomagnetism of Kyoto University. The data processing and a numerical calculation were operated using Data Processing and Analysis System for Geomagnetism of the Kakioka Magnetic Observatory. Finally, the author thanks Dr. J. J. Curto and Prof. O. Saka for their helpful comments for this paper.

\section{References}

Araki, T., Global structure of geomagnetic sudden commencements, Planet. Space Sci., 25, 373-384, 1977.

Araki, T., A physical model of the geomagnetic sudden commencement, in Solar Wind Sources of Magnetispheric Ultra-Low-Frequency Waves, edited by M. J. Engebreston, K. Takahashi, and M. Scholer, pp. 183-200, Geophysical Monograph 81, 1994.

Araki, T., S. Fujitani, M. Emoto, K. Yumoto, K. Shiokawa, T. Ichinose, H. Luehr, D. Orr, D. K. Milling, H. Singer, G. Rostoker, S. Tsunomura, Y. Yamada, and C. F. Liu, Anomalous sudden commencement on March 24, 1991, J. Geophys. Res., 102, 14075-14086, 1997.

Blake, J., W. A. Kolasinski, R. W. Fillus, and E. G. Mullen, Injection of electrons and protons with energies of tens of $\mathrm{MeV}$ into $L<3$ on 24 March 1991, Geophys. Res. Lett., 19, 821-824, 1992.

Itonaga, M., K. Matsuzono, T.-I. Kitamura, I. Toshimitsu, N. B. Trivedi, R. Horita, T. Watanabe, and J. Riddick, Global structure of low-latitude and equatorial geomagnetic pulsations associated with sudden commencements, J. Geomag. Geoelectr., 47, 441-457, 1995.

Iyemori, T. and S. Tsunomura, Characteristics of the association between an SC and a substorm onset, Mem. NIPR Special Issue, No. 26, 139-148, 1983.

Kamide, Y. and S. Matsushita, Simulation studies of ionospheric electric fields and currents in relation to field-aligned currents 1. Quiet periods, J. Geophys. Res., 84, 4083-4098, 1979a.

Kamide, Y. and S. Matsushita, Simulation studies of ionospheric electric fields and currents in relation to field-aligned currents 2. Substorms, $J$. Geophys. Res., 84, 4099-4115, 1979 b.
Kikuchi, T., Evidence of transmission of polar electric fields to the low latitude at times of geomagnetic sudden commencements, J. Geophys. Res., 91, 3101-3105, 1986.

Kikuchi, T. and T. Araki, Horizontal transmission of the polar electric field to the equator, J. Atmos. Terr. Phys., 41, 927-936, 1979.

Kikuchi, T. and T. Araki, Preliminary positive impulse of geomagnetic sudden commencement observed at dayside middle and low latitudes, $J$. Geophys. Res., 90, 12195-12200, 1985.

Kikuchi, T., T. Ishimine, and H. Sugiuchi, Local time distribution of HF Doppler frequency deviations associated with storm sudden commencements, J. Geophys. Res., 90, 4389-4393, 1985.

Kokubun, S., R. L. McPherron, and C. T. Russel, Triggering of substorms by solar wind discontinuities, J. Geophys. Res., 82, 74-86, 1977.

Petrinec, S. M., K. Yumoto, H. Lühr, D. Orr, D. Milling, K. Hayashi, S. Kokubun, and T. Araki, The CME event of February 21, 1994: Response of the magnetic field at the Earth's surface, J. Geomag. Geoelectr., 48, 1341-1379, 1996.

Reiff, P. H., Models of auroral-zone conductances, in Magnetospheric Currents, Geophys. Monogr. Ser., Vol. 28, edited by T. A. Potemra, pp. 180191, AGU, Washington, D.C., 1984.

Rikitake, T. and S. Sato, The geomagnetic Dst field of the magnetic storm on June 18-19, 1936, Bull. Earthq. Res. Inst., Univ. Tokyo, 35, 7-21, 1957.

Russell, C. T. and M. Ginskey, Sudden impulses at subauroral latitudes: Response for northward interplanetary magnetic field, J. Geophys. Res., 100, 23695-23702, 1995.

Russell, C. T., M. Ginskey, and S. M. Petrinec, Sudden impulses at lowlatitude stations: Steady state response for northward interplanetary magnetic field, J. Geophys. Res., 99, 253-261, 1994a.

Russell, C. T., M. Ginskey, and S. M. Petrinec, Sudden impulses at low latitude stations: Steady state response for southward interplanetary magnetic field, J. Geophys. Res., 99, 13403-13408, 1994b.

Sastri, J. H., J. V. S. V. Rao, and K. B. Ramesh, Penetration of polar electric fields to the nightside dip equator at times of geomagnetic sudden commencements, J. Geophys. Res., 98, 17517-17523, 1993.

Sitar, R. J., C. R. Clauer, and E. Friis-Christensen, High-latitude groundbased response to sudden changes in solar wind dynamic pressure, $J$. Geophys. Res., 101, 27001-27013, 1996.

Sugiura, M. and S. Chapman, The average morphology of geomagnetic storms with sudden commencements, Abh. Akad. Wiss. Göttingen, Math.-phys., K1., Sonderheft, Spec. Issue 4, 53 pp., 1960.

Tsunomura, S., On the polarity of SSC and SI observed in low latitudes, Mem. Kakioka Mag. Obs., 26, 15-36, 1995.

Tsunomura, S. and T. Araki, Numerical analysis of equatorial enhancement of geomagnetic sudden commencement, Planet. Space Sci., 32, 599-604, 1984.

Yamada, Y., M. Takeda, and T. Araki, Occurrence characteristics of the preliminary impulse of geomagnetic sudden commencement detected at middle and low latitudes, J. Geomag. Geoelectr., 49, 1001-1012, 1997.

Yumoto, K., Y. Tanaka, T. Oguchi, K. Shiokawa, Y. Yoshimura, A. Isono, B. J. Fraser, F. W. Menk, J. W. Lynn, M. Seto, and $210^{\circ}$ MM Magnetic Observation Group, Globally coordinated magnetic observations along $210^{\circ}$ magnetic meridian during STEP period: 1 . Preliminary results of low latitude Pc3's, J. Geomag. Geoelectr., 44, 261-276, 1992.

Yumoto, K., H. Osaki, K. Fukao, K. Shiokawa, Y. Tanaka, S. I. Solovyev, G. Krymskij, E. F. Vershinin, V. F. Osinin, and $210^{\circ}$ MM Magnetic Observation Group, Correlation of high- and low-latitude Pi2 magnetic pulsations observed at $210^{\circ}$ magnetic meridian chain stations, J. Geomag. Geoelectr., 46, 925-935, 1994.

Yumoto, K. and the $210^{\circ} \mathrm{MM}$ Magnetic Observation Group, Initial results from the $210^{\circ}$ magnetic meridian project-Review, J. Geomag. Geoelectr., 47, 1197-1213, 1995.

Yumoto, K. and the $210^{\circ} \mathrm{MM}$ Magnetic Observation Group, The STEP $210^{\circ}$ magnetic meridian network project, J. Geomag. Geoelectr., 48, 12971309, 1996 .

S. Tsunomura (e-mail: stsunomu@mri-jma.go.jp) 